\title{
EL PROCESO DE ORDENAMIENTO AMBIENTAL EN CUBA. PROPUESTA Y APLICACIÓN DE SU PROCEDIMIENTO METODOLÓGICO A NIVEL NACIONAL Y REGIONAL
}

\author{
O. Cárdenas López \\ Instituto de Geografía Tropical, Ministerio de Ciencias, \\ Tecnología y Medio Ambiente, Cuba \\ obllurys@geotech.cu \\ J.M. Mateo Rodríguez \\ Facultad de Geografía, Universidad de La Habana, Cuba \\ mateo@geo.uh.cu \\ J.M. Martínez Suárez \\ Agencia de Medio Ambiente, Ministerio de Ciencias, \\ Tecnología y Medio Ambiente, Cuba \\ juanmario@ama.cu
}

\begin{abstract}
Resumen: La necesaria interacción entre el ordenamiento territorial y ordenamiento ambiental fue promulgada en la Ley 81 y en las Estrategias Ambientales Nacionales (EAN) desde 1997, en Cuba. Varias situaciones frenaron su cumplimiento, la falta de procedimientos metodológicos que guiaran el proceso, fue una de ellas por lo que la EAN de 2011-2015 y los Lineamientos del Partido Comunista de Cuba (PCC), en el año 2011, lo ratifican como objetivo. En el abordaje de este problema y en la inclusión de los resultados de los estudios de peligro, vulnerabilidad y riesgo y de los escenarios de cambio climático radica la actualidad de la presente investigación. Teniendo como hipótesis que: el empleo de procedimientos metodológicos integradores y participativos facilitará la elaboración de modelos de ordenamiento ambiental (MOA) que aporten regulaciones, lineamientos y normas ambientales al proceso de ordenamiento territorial; se persigue como objetivo principal: proponer los procedimientos metodológicos para la elaboración de los MOA y realizar su validación a nivel nacional y municipal.
\end{abstract}

Recibido: 16-10-14. Aceptado: 5-12-14. 
Son empleados métodos teóricos y empíricos combinados en la elaboración de los procedimientos y en su validación a diferentes escalas. Se concluye en la pertinencia de utilizar el procedimiento propuesto para la elaboración de los MOA, a diferentes escalas, teniendo como base el enfoque participativo y a las unidades de paisaje, como unidad de análisis.

Palabras clave: procedimiento metodológico, ordenamiento ambiental, paisaje, participación.

\begin{abstract}
The necessary interaction between land use and the environment management was enacted in Law 81 and the National Environmental Strategies (EAN) since 1997, in Cuba. Several situations slowed its completion, the lack of methodological procedures that will guide the process, was one of them so the EAN of 2011-2015 and the Guidelines of the PCC, in the year 2011, ratify it as objective. In addressing this issue and the inclusion of the results of studies of hazard, vulnerability and risk and climate change scenarios currently lies of the present investigation. Given the hypothesis that: the use of inclusive and participative methodological procedures will facilitate modeling of environmental management (MOA) to provide regulations, guidelines and environmental standards to land use planning process; main objective is pursued: to propose methodological procedures for the development of the MOA and perform validation at national and municipal levels. Employees are combined theoretical and empirical methods in the development of procedures and their validation at different scales. It was concluded in the relevance of using the proposed procedures for the preparation of the MOA, taking as a basis the participatory approach and the landscape units, as units of analysis.
\end{abstract}

Keywords: methodological procedure, environmental management, landscape, participation.

\title{
1. Introducción
}

La Ley 81 de Medio Ambiente de 1997 en Cuba destacó la necesidad de la incorporación de la dimensión ambiental en los planes y esquemas de desarrollo socioeconómicos cuando proclamó al ordenamiento ambiental como instrumento de la política y la gestión ambiental. Con este planteamiento ratificó la necesidad de un ordenamiento que tuviera en cuenta con mayor profundidad la protección, conservación y restauración de los recursos naturales. En su Capítulo II, Artículo 22, planteó que: "a fin de lograr el desarrollo sostenible del territorio, el ordenamiento ambiental interactúa con el ordenamiento territorial, aportándole lineamientos, regulaciones y normas" Por otra parte, 
el Acuerdo 5863 del 2007, del Comité Ejecutivo del Consejo de Ministros, facultó al Ministerio de Ciencias, Tecnología y Medio Ambiente (CITMA) a poner en vigor la Estrategia Ambiental Nacional (EAN) para el período 2007-2010, lo cual se concretó en la Resolución 40/2007, supliendo algunas de las limitaciones de la primera, planteada en 1997. Esta EAN, ratifica el planteamiento de la Ley 81 y de la anterior, referido al ordenamiento ambiental, con la definición, como objetivo específico, de lograr su interrelación con el ordenamiento territorial, para contribuir al desarrollo sostenible de los territorios elaborando su instrumento metodológico, como una de las acciones primordiales.

Estos enunciados salieron a la luz como vía de solucionar algunas de las dificultades que presentó el proceso de ordenamiento y planificación territorial. A partir del 2010 se puso en marcha la modificación y perfeccionamiento del modelo económico, social y espacial cubano. Con la incorporación de aspectos como el cambio climático, los escenarios de inundaciones costeras por el posible ascenso del nivel medio del mar y los problemas ambientales, en los planes de desarrollo del país, haciéndose necesaria la actualización de los procedimientos e instrumentos jurídicos para el ordenamiento territorial, tratando con mayor énfasis la dimensión ambiental. La EAN, para el período 2011-2015, retomó los principales presupuestos de las anteriores, incluyó los lineamientos y metas del Programa Nacional de Enfrentamiento al cambio climático del 2007 y ratificó la necesidad de lograr la interrelación entre el ordenamiento ambiental y el territorial; además, añadió como nuevo objetivo el de incorporar los resultados de los estudios de peligro, vulnerabilidad y riesgo y los escenarios de cambio climático, al ordenamiento territorial.

Envueltas en la situación anteriormente expuesta son varias las instituciones científicas, planificadoras y educacionales que han desarrollado una vasta experiencia en la realización de estudios e investigaciones ambientales, entre ellas destacan la Facultad de Geografía de la Universidad de La Habana, las pertenecientes al CITMA, subordinadas o no a la Agencia de Medio Ambiente (AMA), el Instituto de Planificación Física (IPF) y sus representaciones provinciales y municipales. Todas persiguen como fin común la sostenibilidad ambiental, aunque desde enfoques y metodologías diferentes. Esto ha dado como resultado la existencia de gran cantidad de investigaciones que, cumpliendo sus objetivos particulares, son sectorizadas y parciales y en ocasiones no se han complementado en sus resultados territoriales.

La incorporación efectiva de la dimensión ambiental en el proceso de ordenamiento territorial, mediante la interacción del ordenamiento ambiental y el territorial, declarada en la Ley 81 y en las EAN, aún no se ha logrado. Entre los aspectos que han condicionado esta situación y que requieren de una sustentación científica se encuentran: la existencia, reconocida por ley de dos ordenamientos en Cuba, el territorial y el ambiental; la existencia y empleo de varios enfoques metodológicos en los estudios ambientales y territoriales, con diferentes salidas de los resultados y el empleo de diferentes unidades de análisis; el carácter formal y no efectivo que posee la participación de los actores a diferentes niveles; la carencia y dispersión de información territorial y la falta de un cuerpo legal vinculante para integrar el ordenamiento ambiental y el territorial. 
Por lo anterior la presente investigación se propone aportar un procedimiento metodológico para llevar a cabo el proceso de ordenamiento ambiental en Cuba, utilizando como base el análisis e integración de metodologías empleadas en los estudios ambientales y territoriales anteriores; la participación de los actores territoriales, durante todas las fases de trabajo, en particular, mediante la realización de talleres de elaboración, debate y aprobación de los resultados, con el empleo de técnicas participativas no utilizadas en este tipo de investigación con anterioridad; la incorporación de los resultados de los estudios de peligro, vulnerabilidad y riesgo, de los escenarios de cambio climático y el cumplimiento de la legislación ambiental, como aspectos claves para evaluar las limitaciones ambientales de uso, los usos potenciales y los problemas ambientales y la propuesta. Como resultado del procedimiento se conformará el MOA que proporcionará orientación a los instrumentos administrativos y técnicos de los territorios sobre la base del uso más eficiente de sus sistemas ambientales, para contrarrestar las afectaciones que ponen en peligro su desarrollo sostenible, mediante la propuesta de políticas, usos ambientalmente recomendados, lineamientos, regulaciones y normas ambientales, diferenciados por sistemas ambientales y sectores claves del territorio.

\section{Tratamiento de los aspectos teóricos y metodológicos del ordenamiento ambiental en Cuba}

En Cuba, desde el año 1960, el ordenamiento territorial se realiza a partir de las políticas del Estado y del Gobierno, como estrategia para obtener los bienes materiales que contribuyan al desarrollo socioeconómico sostenible y endógeno del territorio. La responsabilidad del planeamiento del uso de la tierra se comparte entre varias instituciones y el IPF lo consuma mediante el control y aplicación de las políticas territoriales. En el año 1997 es declarado el ordenamiento ambiental, en la Ley 81 de Medio Ambiente, como uno de los instrumentos de la política y de la gestión ambiental del CITMA. A partir de las estrategias ambientales nacionales y de la propia Ley se declara la necesaria interacción entre ambos ordenamientos.

Vicente da Silva, Mateo y De Andrade (2011), aseguran que en las investigaciones y estudios recientes se aceptan por lo menos tres categorías de planificación: la sectorial, que incluye los procesos de planeamiento económico y social, pretendiendo planificar la organización funcional y espacial de las diferentes actividades humanas; la ambiental, cuyo objetivo es establecer la organización funcional y espacial de determinadas áreas en dependencia de las características de los sistemas naturales y la territorial, que programa la articulación entre las anteriores formas de planificación, en determinados territorios, considerados como espacios de poder y de identidad cultural propia.

En Cuba, el ordenamiento territorial es un proceso administrativo cuyo fin es lograr el desarrollo integral del territorio, mientras que el ambiental se rige por las políticas 
ambientales para lograr el desarrollo ambientalmente sostenible del mismo, ambos tienen como finalidad la elevación de la calidad de vida y el desarrollo sostenible.

En la Ley 81 y en la EAN para el período 2011-2015 queda definido que el proceso de ordenamiento ambiental está destinado a asegurar el desarrollo ambientalmente sostenible del territorio analizando integralmente los recursos bióticos y abióticos y los factores socioeconómicos; aportando las normas, regulaciones y lineamientos ambientales para el manejo. Para lograr esto debe incluir en sus estudios los ecosistemas existentes en el territorio, los recursos naturales, los desequilibrios ecológicos provocados por diferentes causas, la relación entre las actividades humanas y sus condiciones ambientales, las áreas protegidas y sus zonas de amortiguamiento y el impacto ambiental de las nuevas actividades y construcciones.

Para la realización de los estudios ambientales son varios los enfoques metodológicos utilizados. Estos varían en dependencia de la concepción filosófica y metodológica de los especialistas que lo realicen, pero todos con el objetivo de orientar la utilización racional de los recursos del territorio teniendo en cuenta sus limitaciones y potenciales, las incompatibilidades de uso y los problemas ambientales para lograr al desarrollo sostenible. Las metodologías analizadas están conformadas por una serie de fases o etapas de trabajo que se desarrollan de forma consecutiva e interactiva, con ligeras variaciones entre sí. Estas fases, por lo general, son: la preparatoria u organizativa, la de caracterización, la de análisis, la de diagnóstico, la prospectiva, la propositiva, la de gestión y la de control.

La mayor parte de dichas metodologías reconocen como objeto de estudio al territorio y lo abordan a partir de su división en tres temáticas: medio natural, medio social y medio económico (con algunas variaciones en la denominación de cada aspecto); organizan el trabajo en etapas o fases y aportan como resultado modelos y planes de desarrollo.

Las unidades de análisis más utilizadas son las naturales (suelos, formaciones vegetales, cuencas, paisajes, geosistemas, ecosistemas), las político-administrativas (estados, provincias, municipios) y las de producción (fincas, lotes forestales, etc.).

El enfoque geosistémico fue enunciado por Sochava en el año 1978, desarrollando una interpretación sistémica de la Teoría de los Paisajes y de los Complejos Territoriales Naturales y Productivos en varios niveles. Según esta los geosistemas naturales son la parte de la superficie terrestre, en la que los componentes individuales de la naturaleza se encuentran en relación estrecha unos con otros y, como un todo, interactúan con los espacios vecinos de la esfera cósmica y de la sociedad humana.

Según Mateo (1991) y Salinas (2000) el paisaje geográfico, como categoría científica general de carácter transdisciplinario, se concibe como un sistema espacio-temporal, complejo y abierto, que se origina y evoluciona justamente en la interfase naturaleza-socie- 
dad, en un constante estado de intercambio de energía, materia e información, donde su estructura, funcionamiento, dinámica y evolución reflejan la interacción entre los componentes naturales (abióticos y bióticos), técnico-económicos y socio-culturales.

En la presente investigación se asume como unidad de análisis a los paisajes (UP). Se parte de considerarlos como paisajes culturales, siendo producto de la interacción y articulación dialéctica entre los paisajes naturales y los antroponaturales. Los paisajes naturales son el conjunto de los componentes naturales (estructura geológica, relieve, clima, aguas, suelos, vegetación y mundo animal) que se interrelacionan de manera dialéctica en una determinada porción del espacio de la superficie terrestre y el paisaje antroponatural refleja la forma en que las relaciones humanas han modificado, transformado, decorado y construido el espacio natural.

\section{Propuesta de procedimiento metodológico para la elaboración del modelo de ordenamiento ambiental}

El procedimiento metodológico orienta el proceso de elaboración de los MOA. Independientemente del perfil científico del equipo de trabajo que lo realice se deben abordar todas las fases propuestas, según la escala de trabajo, para lograr uniformidad en los resultados que se obtengan (Figura 1).

Su visión analiza las interrelaciones entre las variables y tienen en cuenta los procesos y cambios que determinan el estado actual y futuro de los recursos naturales y las formas de asimilación del territorio. En la siguiente figura aparecen las fases de trabajo. Nótese que está ausente la fase de ejecución o gestión, presente en las metodologías analizadas, debido a que en el proceso de integración con el ordenamiento territorial es este quien, por el Decreto 21 de 1978: Reglamento sobre la Planificación Física, es el encargado de proponer el destino final del suelo a todos los niveles, además, se insiste en la participación de los actores durante todo el proceso.

La elaboración del MOA se desarrolla sobre la base de la participación de los actores dirigida por un equipo multidisciplinario de investigadores y técnicos, mediante la realización de consultas, entrevistas, conversatorios. En los talleres participativos se exponen, discuten y aprueban los resultados de cada fase, desde su inicio y se orienta metodológicamente la siguiente fase de trabajo. La presencia de los actores y decisores del territorio es un componente imprescindible del proceso de ordenamiento ambiental, pues es un recurso que otorga legitimidad y favorece la viabilidad de los resultados, asegurando el aprovechamiento de sus conocimientos y su compromiso.

El MOA es elaborado en un gabinete de inicio, con el trabajo de campo y en un gabinete final. Durante el gabinete de inicio se realiza la consulta del material bibliográfico 


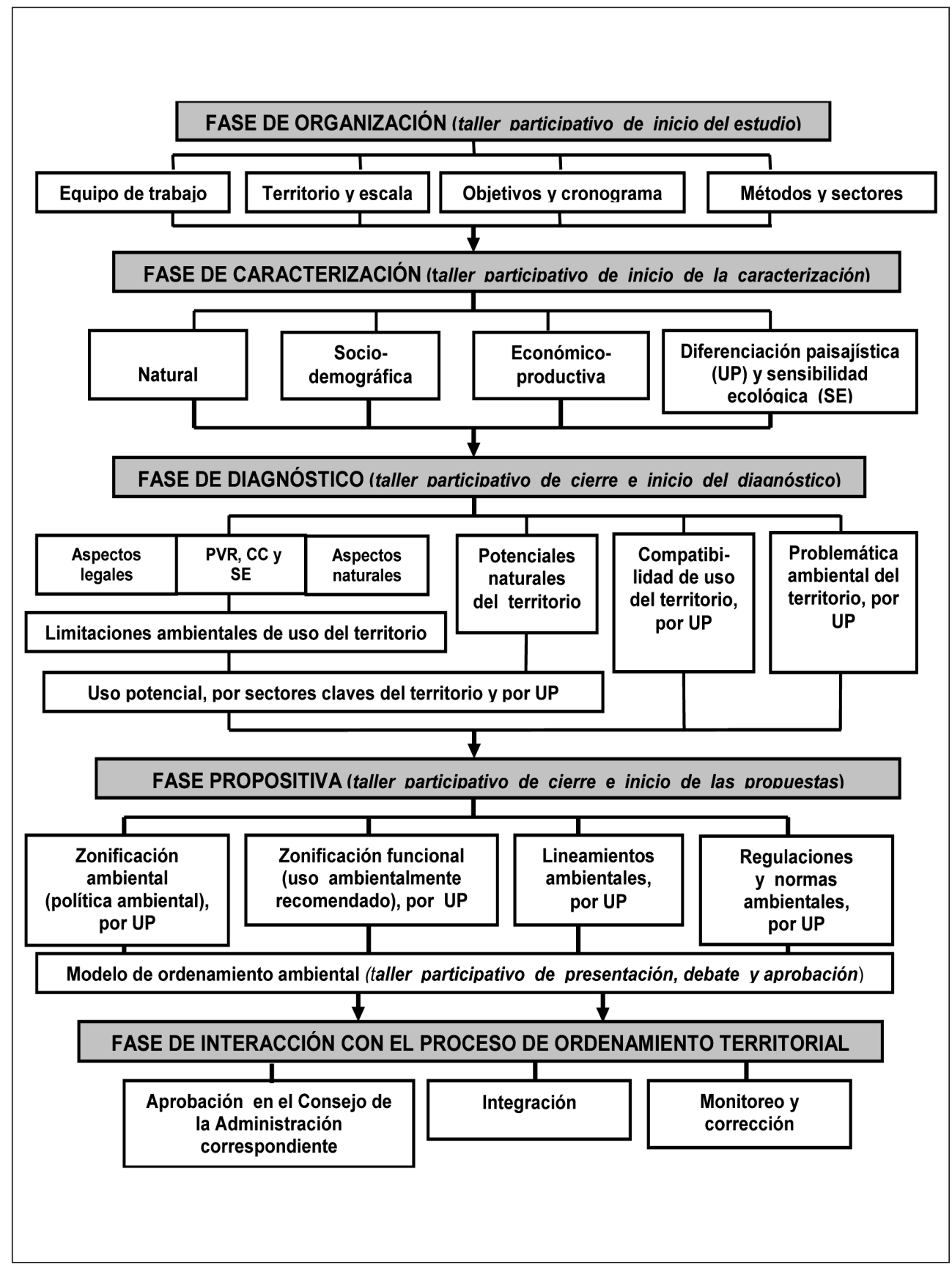

Figura 1. Fases metodológicas para la elaboración del modelo de ordenamiento ambiental. 
y cartográfico relacionado con los territorios y se elaboran los informes preliminares y los mapas de apoyo. Esta información se comprueba y complementa en el campo, con recorridos por el territorio y con la realización de talleres participativos (Carranza, 2006).

En el gabinete final se realizan las evaluaciones y rectificaciones pertinentes para, en talleres posteriores, provocar la discusión y aprobación de los resultados y finalizando el trabajo con la propuesta de las políticas ambientales, usos ambientalmente recomendados, lineamientos, regulaciones y normas ambientales, por UP. Los análisis y la salida cartográfica son facilitadas por el empleo de los SIG.

Las características físico-geográficas y socioeconómicas, las divisiones y los recortes territoriales naturales y político-administrativos de Cuba (Iñiguez, 2014) y la clasificación de los planes físicos del ordenamiento territorial (IPF, 1998) permiten definir para el ordenamiento ambiental tres escalas: la nacional, la regional y la local, que se corresponden con las utilizadas en el proceso de ordenamiento territorial. Para el MOA nacional, con escalas territoriales de 1:500 000, 1:250 000, 1:100 000), se parte de las localidades de paisaje, estas se consideran como un conjunto de meso formas del relieve asociados al mismo tipo de mega relieve, con un tipo de clima predominante y un tipo estructuro-litológico predominante; para el regional, con escalas territoriales de 1:50 000 y 1: 25 000), se parte las comarcas y sub comarcas, las primeras se consideran como las partes de las meso formas del relieve y para el local, con escalas territoriales de 1:10 000, 1:5 000 y de más detalle, se parte de las sub comarcas, las cuales se sub dividen en los tipos de facies, que son los elementos de las partes de la meso forma del relieve.

Para lograr un mayor entendimiento entre el grupo de trabajo y los actores territoriales se pueden nombrar como unidad de primer orden a la región y de segundo orden a la localidad, en la escala nacional; en la escala regional, como unidad de primer orden a la comarca y de segundo orden a la sub comarca y, en la escala local, como unidad de primer orden a la sub comarca y de segundo orden a la facie.

\section{Resultados: Modelos de los territorios seleccionados}

\subsection{MOA del territorio emergido de la República de Cuba}

La República de Cuba es un archipiélago constituido por la mayor isla de las Antillas, Cuba, la Isla de la Juventud y otros cayos, islotes e islas adyacentes. Está ubicada en el mar Caribe. Limita al norte con el estrecho de la Florida, al este con el Paso de los Vientos, al sur con el mar Caribe y el oeste con el golfo de México. Posee una superficie de $109886 \mathrm{~km}^{2}$. Sus costas se extienden $6000 \mathrm{~km}$.

El relieve se caracteriza por la presencia de terrazas marinas y fluviales, el desarrollo del carso y las costas biogénicas. Predominan las llanuras, en un 75\%, seguido por las 
alturas bajas y montañas bajas y medias. Las llanuras son planas o ligeramente onduladas, con alturas inferiores a los $150 \mathrm{~m}$, en ellas reside el mayor por ciento de la población y de sus actividades económicas. Las principales elevaciones son: la cordillera de Guaniguanico, al occidente de Cuba en la provincia de Pinar del Río, formada por la sierra de los Órganos y la del Rosario; el grupo Guamuahaya, en la parte central de la isla correspondiente a las provincias de Cienfuegos, Sancti Spíritus y Villa Clara, compuesto por la sierra del Escambray y la de Trinidad; el sistema Bamburanao en Villa Clara, Sancti Spíritus y Ciego de Ávila, abarca a un grupo de elevaciones de las alturas del nordeste de las Villas, la sierra de Bamburanao, la sierra de Meneses y Cueto, la loma de la Canoa y la sierra de Jatibonico; el sistema montañoso de la Sierra Maestra, al sur de las provincias de Guantánamo, Santiago de Cuba y Granma, posee en el Pico Turquino (1 972 m) la máxima altura del país; y, por último, el grupo montañoso NipeSagua-Baracoa, al noroeste del oriente de Cuba, incluyendo partes de las provincias de Guantánamo, Santiago de Cuba y Holguín.

El clima de Cuba es cálido tropical estacionalmente húmedo, con influencia marítima. Entre los eventos meteorológicos que con mayor frecuencia afectan a la isla están los huracanes, frentes fríos y sures, con mayor afectación en la región occidental del país. Los valores medios anuales de la temperatura oscilan desde $24^{\circ} \mathrm{C}$ en las llanuras, hasta $26^{\circ} \mathrm{C}$ y más en las costas orientales, observándose una disminución de los valores en las áreas correspondientes a los principales sistemas montañosos. El elemento de mayor variabilidad son las precipitaciones, su acumulado medio anual es de 1335 $\mathrm{mm}$. En la mayor parte del territorio, el año se divide en dos períodos estacionales, el lluvioso (de mayo a octubre) donde se registra aproximadamente el $80 \%$ del total anual, y el poco lluvioso (de noviembre a abril) con el $20 \%$ restante. La humedad relativa es normalmente alta, con valores por encima del $60 \%$.

De acuerdo con la IV versión de la Clasificación Genética de suelos de Cuba (Hernández, et al., 1999), se reconocen 14 agrupamientos, 36 tipos genéticos y 172 subtipos de suelos. El agrupamiento de suelos más abundante en Cuba es el pardo sialítico, con el 26,82\% del total, seguido por el ferralítico y fersialítico, mientras que los de menor superficie la poseen el histosol, el ferrálico y el halomórfico.

La forma alargada y estrecha, la compleja geología y la disposición de los macizos orográficos determinan las características del drenaje superficial en la isla de Cuba, que cuenta con 633 corrientes fluviales que desembocan superficial o subterráneamente al mar. De estas 272, drenan un territorio de $32283 \mathrm{~km}^{2}$, hacia el golfo de México y el Atlántico Norte; 361 lo hacen hacia la cuenca del mar Caribe, drenando un territorio de $48860 \mathrm{~km}^{2}$. El territorio que resta $\left(26002 \mathrm{~km}^{2}\right)$ pertenece a áreas sin drenaje fluvial definido, terrenos carsificados, ciénagas, manglares, etc.

Cuba ocupa el primer lugar en las Antillas por el endemismo de plantas superiores. Entre los endémicos valiosos se pueden citar: la palma corcho, el marañón de la maestra 
o mantequero (un árbol antiquísimo, de los primeros con flores y superviviente de la flora del cretáceo; la palma barrigona, la dracena cubana, el aguacate cimarrón, gigantesca cactácea; el pino de Mayarí, el pino de la Maestra. La vegetación presenta diferentes tipos de bosques, matorrales, herbáceas, complejos de vegetación y manglares, encontrando además el algarrobo de olor, entre otros. La fauna tiene características muy notables debido a su origen y evolución, así como a la influencia del territorio que no presenta barreras naturales. Es pobre en cuanto a grupos representados, pero muchos de los que existen están muy diversificados y con tendencia a la microlocalización (endemismo).

En diciembre del 2011 la Oficina Nacional de Estadísticas e Información (ONEI, 2011a) reportó una población de 11247925 habitantes, 5632915 hombres y 5615010 mujeres. Las proyecciones realizadas hasta el 2025 concuerdan en el decrecimiento de la población, que para esa fecha será de 11 134 685. Se evidencia una reducción de la proporción de habitantes entre las edades de 0 y 14 años y el incremento de los tramos de 15 a 59, y de 60 y más años y el continuado descenso de la fecundidad, proceso que comienza a evidenciarse desde 1978. Los datos de cierre del 2005, indican que la tasa de fecundidad cayó a 0.7 , por lo que no está garantizado el reemplazo de la población.

La EAN (2007-2010) resumió el panorama ambiental cubano caracterizado por las transformaciones en sectores clave de la economía señalando el reordenamiento de la industria azucarera como una necesidad del país para lograr la producción de caña y alimentos, a través de la liberación de tierras en usufructo y la diversificación de las producciones agropecuarias; el incremento en la producción y empleo de petróleo y gas; la consolidación de la agricultura sostenible; el impulso a la acuicultura y el maricultivo; el sostenido desarrollo del turismo de naturaleza; el proceso de fortalecimiento paulatino del manejo integrado de la zona costera en su vínculo con el desarrollo económico y social y con la protección del medio ambiente; el incremento de la conciencia social acerca de los problemas ambientales; el nivel de implementación de la Ley 81 de Medio Ambiente y los avances en la política ambiental internacional, reflejados en nuevos instrumentos en materia de productos químicos, bioseguridad y cambio climático, entre otros (Fernández, et al., 2009).

En cuanto a los paisajes, puede decirse que sus factores diferenciadores son la insularidad, la complejidad del basamento geólogo-geomorfológico y la diversidad litológica y la situación geográfica del archipiélago (Salinas, 1989, pp. 201-477). Cuba se caracteriza por el predominio de las llanuras desarrolladas en rocas carbonatadas y por las montañas bajas húmedas, que superan en espacio a las medias, que solo ocupan el 1\% del territorio (Mateo, et al,. 1989, p. XII 1.2-3) (Tabla 1 y Figura 2).

Las UP de mayor sensibilidad ecológica son la 1, 2.5, 3, 4.2 y 4.3 y las menos sensibles son las 2.3, 2.4 y 4.1 . 
Tabla 1. Unidades de paisaje del territorio emergido de la República de Cuba

\begin{tabular}{|c|c|}
\hline$U P$ & Descripción \\
\hline 1 & $\begin{array}{l}\text { Llanuras secas y medianamente secas } \\
\text { - Abrasivo acumulativas sobre roca sedimentaria, carbonatada y depósitos } \\
\text { - Acumulativas aluviales y estructuro-denudativas sobre eluvio de rocas sedimentarias } \\
\text { carbonatadas, volcánicas y vulcanógeno-sedimentarias }\end{array}$ \\
\hline 2 & Llanuras medianamente húmedas \\
\hline 2.1 & $\begin{array}{l}\text { Llanuras carsificadas sobre roca sedimentaria carbonatada: Presentan superficies planas } \\
\text { y poco diseccionadas con escurrimiento básicamente subterráneo y desarticulación del } \\
\text { drenaje superficial. Se diferencian los que presentan suelos poco desarrollados con bos- } \\
\text { ques semideciduos y especies micrófilas y espinosas y los que presentan suelos pro- } \\
\text { fundos y evolucionados con bosques semideciduos que han sido completamente sus- } \\
\text { tituidos por la agricultura, principalmente por caña de azúcar y cultivos. }\end{array}$ \\
\hline 2.2 & $\begin{array}{l}\text { Llanuras acumulativas arenosas y semiarenosas sobre roca sedimentaria carbonatada: Se } \\
\text { distribuyen en los espacios que circundan a algunos macizos montañosos y antiguos } \\
\text { núcleos geoanticlinales. Se caracterizan por la existencia de un sustrato rico en cuarzo } \\
\text { y caolín, con suelos ácidos, de textura arenosa con concreciones ferruginosas. Predo- } \\
\text { minan las especies de pinos y palmeras. Sus condiciones ecológicas son extremas. }\end{array}$ \\
\hline 2.3 & $\begin{array}{l}\text { Llanuras erosivas y erosivo-denudativas sobre rocas variadas: Se caracterizan por su re- } \\
\text { lieve llano, diseccionado, ondulado con buen drenaje y bosques semideciduos y plan- } \\
\text { taciones de caña y pastizales en suelos pardos sialíticos con buena cantidad de nutrientes } \\
\text { y materia orgánica. Los desarrollados sobre serpentinita presentan suelos poco desa- } \\
\text { rrollados con formaciones arbustivas micrófilas y espinosas. }\end{array}$ \\
\hline 2.4 & $\begin{array}{l}\text { Llanuras denudativas sobre rocas vulcanógenas, vulcanógeno-sedimentarias e intrusi- } \\
\text { vas: Están ampliamente distribuidas en el país. Tienen suelos pardos sialíticos y fuerte } \\
\text { actividad agropecuaria, en sustitución de los bosques semideciduos. }\end{array}$ \\
\hline 2.5 & $\begin{array}{l}\text { Llanuras pantanosas sobre depósitos turbo-margosos: Presentan humedecimiento ex- } \\
\text { cesivo, estancamiento de las aguas y predominio de condiciones anaeróbicas. Su relieve } \\
\text { es llano de origen deltaico o marino-palustre, con formación de fangos orgánico-mi- } \\
\text { nerales y arcillas carbonatadas, con acumulación de turba limitada. Predominan los her- } \\
\text { bazales, manglares y los bosques húmedos. }\end{array}$ \\
\hline 2.6 & $\begin{array}{l}\text { Llanuras semipantanosas o aluviales sobre depósitos arcillosos y arenosos: Tienen ori- } \\
\text { gen acumulativo. Están expuestas a inundaciones ocasionales y estacionales. Formadas } \\
\text { por depósitos arcillosos, generalmente gleyzadas con suelos de carácter sialítico, arci- } \\
\text { llosos, plásticos y salinizados. La vegetación natural está constituida por bosques de he- } \\
\text { lechos, árboles perennifolios y palmares. Predominan las plantaciones de caña, los arro- } \\
\text { zales y los pastizales. }\end{array}$ \\
\hline
\end{tabular}




\begin{tabular}{|c|c|}
\hline$U P$ & Descripción \\
\hline 3 & $\begin{array}{l}\text { Colinas, alturas y montañas secas: } \\
\text { - Colinas y alturas denudativo cársicas sobre rocas sedimentarias carbonatadas y terrí- } \\
\text { geno-carbonadas } \\
\text { - Colinas y alturas estructuro denudativas sobre rocas vulcanógno-sedimenarias } \\
\text { - Macrovertientes meridionales denudativo-erosivas de las montañas bajas sobre rocas } \\
\text { sedimentarias terrígeno-carbonatadas y metamórficas } \\
\text { - Macrovertientes erosivo-denudativas sobre rocas volcánicas, vulcanógeno-sedimen- } \\
\text { tarias y metamórficas }\end{array}$ \\
\hline 4 & Depresiones intermontañosas, colinas, alturas y montañas bajas húmedas \\
\hline 4.1 & $\begin{array}{l}\text { Depresiones intermontañosas: Poseen suelos ferralíticos y pardos sialíticos con cultivos, } \\
\text { pastos y bosque siempre verde. } \\
\text { - Llanuras de las depresiones estructuro-denudativas y cársicas sobre rocas sedimen- } \\
\text { tarias, carbonatadas, terrígeno-carbonatadas y metamórficas } \\
\text { - Llanuras de las depresiones estructuro-fluviales y erosivas sobre depósitos aluviales } \\
\text { de rocas vulcanógeno-sedimentarias y metamórficas }\end{array}$ \\
\hline 4.2 & $\begin{array}{l}\text { Colinas, alturas y montañas bajas húmedas: En rocas sedimentarias presentan suelos pardos } \\
\text { sialíticos, ferralíticos y litosoles con pastos, bosque semideciduo y vegetación de mogotes. } \\
\text { En rocas metamórficas, volcánicas y sedimentarias presentan suelos lateríticos, ferralíticos y } \\
\text { pardos sialíticos con pastos, matorrales y bosque semideciduo, siempreverde y pinares. } \\
\text { - Colinas y alturas denudativo-cársicas sobre rocas sedimentarias, terrígeno-carbonata- } \\
\text { das y carbonatadas } \\
\text { - Colinas y alturas denudativas sobre rocas metamórficas, vulcanógeno-sedimentarias } \\
\text { y volcánicas } \\
\text { - Montañas bajas denudativo-cársicas sobre rocas sedimentarias carbonatadas y meta- } \\
\text { mórficas } \\
\text { - Montañas bajas denudativas sobre rocas volcánicas, vulcanógeno-sedimentarias, se- } \\
\text { dimentarias terrígeno-carbonatadas y metamórficas } \\
\text { - Montañas bajas denudativas sobre roca metamórfica y vulcanógeno-sedimentarias } \\
\text { - Alturas de roca sedimentaria carbonatada } \\
\text { - Alturas denudativas de rocas vulcanógeno-sedimentaria, volcánica y sedimentarias te- } \\
\text { rrígeno-carbonatadas }\end{array}$ \\
\hline 4.3 & $\begin{array}{l}\text { Montañas medias húmedas: Comprenden las alturas y montañas bajas, se caracterizan } \\
\text { por la alta pluviosidad permanente y el predominio de bosques perennifolios. La ve- } \\
\text { getación natural está compuesta por arbustos y bosques de altura reducida, vegetación } \\
\text { perennifolia y micrófila. } \\
\text { - Montañas medias estructuro-erosivas sobre rocas metamórficas } \\
\text { - Montañas medias estructuro-denudativas sobre rocas volcánicas y metamórficas }\end{array}$ \\
\hline
\end{tabular}

Fuente: Elaborado por la autora a partir de Mateo, et al. (1989). 


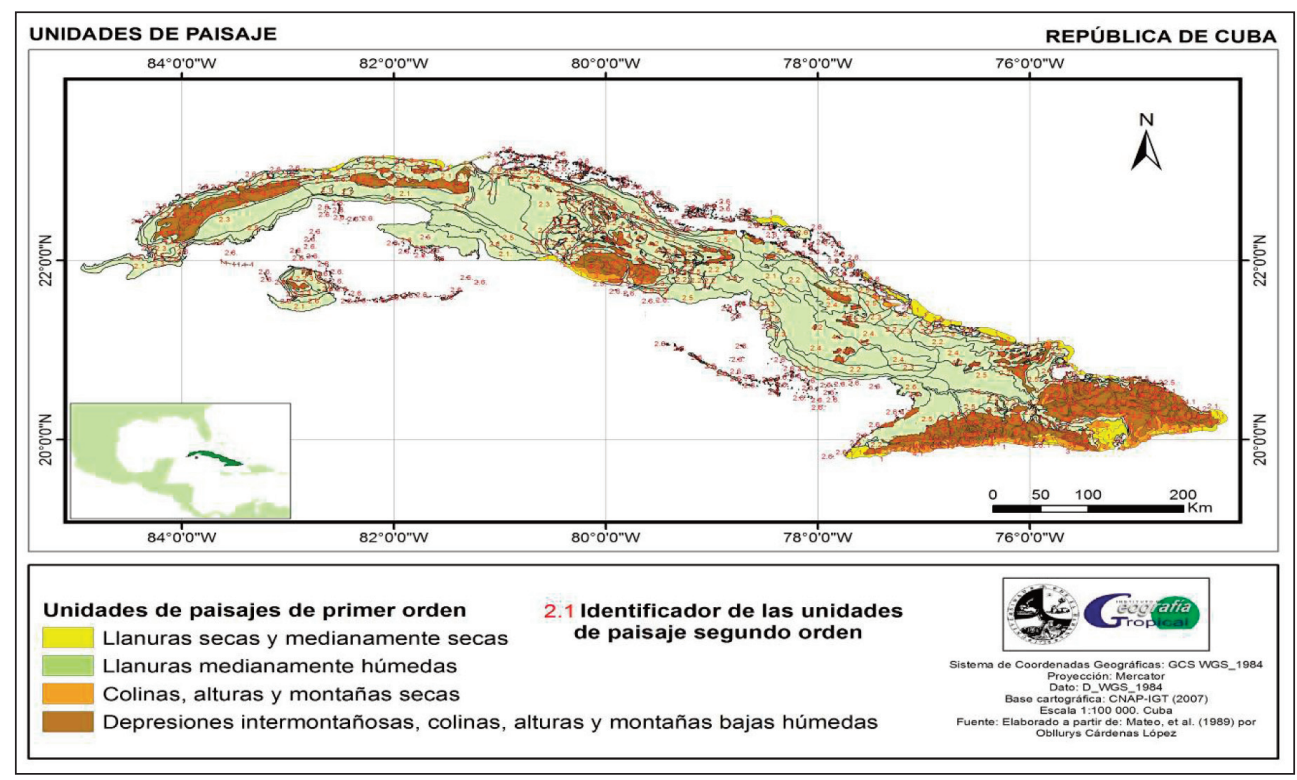

Figura 2. Unidades de paisaje del territorio emergido de la República de Cuba.

\subsubsection{Identificación de las limitaciones ambientales de uso}

Las limitaciones del territorio para el desarrollo de la agricultura y la ganadería vienen dadas fundamentalmente por la baja agroproductividad de los suelos; por los escenarios climáticos y los resultados de los estudios de peligro, vulnerabilidad y riesgo y por la alta sensibilidad ecológica. El hecho de que Cuba sea un archipiélago hace que los impactos asociados con el ascenso del nivel del mar puedan clasificar como los más importantes. Según estimados del IPF (2007) esta situación afectará a nuevos territorios agrícolas y pecuarios, los humedales sufrirán un desplazamiento tierra adentro, ocurrirá un aumento de la salinidad en los estuarios y de la intrusión marina, se alterará la amplitud de la marea en ríos y bahías, se alterarán los patrones de sedimentación y aumentará la aridez. Los escenarios de variabilidad y cambio climático indican que las magnitudes de la temperatura media anual del aire se pudieran incrementar paulatinamente hasta alcanzar magnitudes entre $1,6^{\circ} \mathrm{C}$ y $2,5^{\circ} \mathrm{C}$, para el año 2100 , y el aumento de la aridez. En el caso del nivel del mar, las proyecciones indican incrementos en el orden de 8 a $44 \mathrm{~cm}$, para el año 2050 y de $20 \mathrm{~cm}$ a $95 \mathrm{~cm}$, para el año 2100 (IPF, 2007).

Las limitaciones para la UP 1 están relacionadas, principalmente, con la pérdida de territorios según los resultados de los estudios de peligro, vulnerabilidad y riesgo y los escenarios climáticos; con la baja agroproductividad de los suelos y su tendencia a la salinización y la prevalencia de una larga estación seca. La UP 2 está limitada por la 
presencia de suelos de baja capacidad agroproductiva (2.1, 2.2, 2.3 sobre serpentinita y la 2.4) y la 2.5 y 2.6 por los escenarios climáticos y los estudios de peligro, vulnerabilidad y riesgo y la tendencia a la salinización de los suelos y el agua. La UP 3 está limitada por la existencia de precipitaciones escasas, por la presencia de suelos poco evolucionados y pedregosos, la incidencia de procesos erosivos y denudativos y por la presencia de fuertes pendientes. La 4.2 y la 4.3 presentan limitaciones de fuertes pendientes y suelos pedregosos, además, la 4.3 presenta alta pluviosidad permanente.

Todas las UP poseen algún tipo de limitación determinada por la legislación ambiental. De esta forma, las que presentan altos valores naturales y patrimoniales (1, 2.3 sobre serpentinita, 2.5, 3, 4.2 y 4.3), teniendo o no declarados sus territorios como áreas protegidas, deben tener limitado su uso a la conservación y la protección, con muy bajos aprovechamientos en los sectores agrícola y pecuario. Unido a lo anterior clasifican como muy sensibles la 1, 2.5, 3, 4.2 y 4.3 .

\subsubsection{Identificación del uso potencial}

Teniendo en cuenta la agroproductividad, los suelos más productivos se localizan en La Habana y Ciego de Ávila, los menos productivos en Granma, Pinar del Río, Holguín, Santiago de Cuba y Guantánamo y los intermedios Camagüey, Las Tunas, Sancti Spíritus, Cienfuegos, Matanzas y Villa Clara. En cambio, la zona costera y las regiones montañosas albergan los más altos valores naturales para conservar y proteger. Por lo tanto, las de mayor potencial para la agricultura son la 2.3, 2.4, 2.6 y 4.1 y para el sector pecuario la 2.1, 2.2, 2.3, 2.4 y 4.1 .

\subsubsection{Identificación de la problemática ambiental}

Teniendo en cuenta los resultados de los estudios realizados la UP 2 se corresponde con el tipo de paisaje más degradado de Cuba. En ella se manifiestan principalmente los procesos de erosión, acidez y salinidad, reportando una pérdida en su cubierta vegetal en más del 73\% de su área total. Posee abundantes áreas dedicadas al cultivo de la caña de azúcar, a pastos naturales y cultivados y a cultivos menores, más del 80\% de los asentamientos urbanos se encuentran en estas llanuras con una densidad de población mayor de 6000 hab/ $\mathrm{km}^{2}$, unido a las redes viales. La 3 y la 4.1 le siguen en degradación, por el grado de manifestación de la erosión en categorías extremas y la pérdida en más del 50\% de su cubierta vegetal original.

Con la degradación más baja se encuentran la 1 y la 4.3, aunque también manifiestan procesos de erosión y acidez de los suelos y reportan un cambio en alrededor del 40\% de su área, con respecto a su vegetación original. 


\subsubsection{Conformación del modelo de ordenamiento ambiental}

En las UP 1, 2.5, 3, 4.2 y 4.3 prevalece la política ambiental de protección y conservación dirigida a mantener sus altos valores ambientales y los servicios ambientales que brinda a la naturaleza y a la sociedad y por su alta sensibilidad. Es de destacar que la 1 es una de las más vulnerables a los eventos hidrometeorológicos extremos y a los escenarios de variabilidad climática por inundaciones costeras, por lo que no debe desarrollarse en esta la agricultura y la ganadería.

La política de aprovechamiento prevalece en la 2.1, 2.2, 2.4 y 4.1, con uso recomendado de agricultura en la 2.3, 2.4, 2.6 y 4.1 y pecuario en la 2.1 y en la 2.2. La política de protección y conservación prevalece en la UP 2.5 con vistas a mantener y asegurar los servicios ambientales que proporcionan siendo, además, una de las más vulnerables a los eventos hidrometeorológicos extremos y a los escenarios de variabilidad climática por inundaciones costeras, con sensibilidad alta. La política de restauración se dispone en la UP 2.3, la más extendida de Cuba, y en la 2.6, por el estado en que se encuentran los suelos, dedicados históricamente a la agricultura.

En la Figura 3 aparece el modelo de ordenamiento ambiental propuesto.

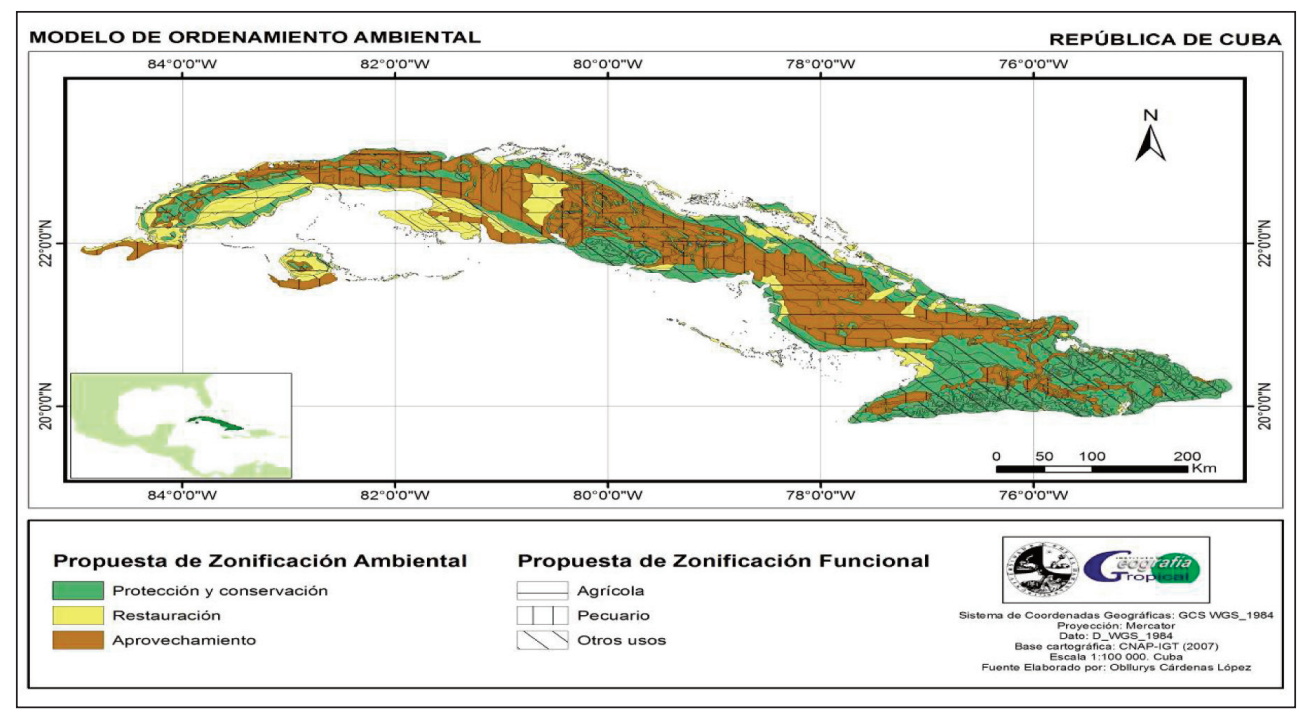

Figura 3. Modelo de ordenamiento ambiental del territorio emergido de la República de Cuba (sector agrícola y pecuario). 


\subsubsection{Interacción con el proceso de ordenamiento territorial}

Una vez concluido el análisis de los restantes sectores, determinados por el equipo de trabajo, de forma integral será presentado el MOA a las instancias pertinentes, para su debate y aprobación. A continuación se pondrá a disposición del IPF. El CITMA, mediante el equipo de trabajo, deberá monitorear el cumplimiento de las propuestas realizadas y corregirlas y adecuarlas.

\subsection{MOA del municipio Yagüajay, provincia de Sancti Spíritus}

El municipio pertenece a la provincia de Sancti Spíritus, tiene una extensión superficial de $1041,820 \mathrm{~km}^{2}$. Se encuentra situado entre los $21^{\circ} 06^{\prime} 00^{\prime \prime}$ y $21^{\circ} 28^{\prime} 00^{\prime \prime}$ de latitud norte y los $78^{\circ} 57^{\prime} 00^{\prime \prime}$ y $80^{\circ} 35^{\prime} 00^{\prime \prime}$ de longitud oeste. Limita al sureste con la provincia de Ciego de Ávila, al suroeste con la provincia de Villa Clara, al norte con el océano Atlántico y al sur con los municipios de Cabaiguán y Taguasco de la propia provincia.

En él predominan las formaciones de rocas sedimentarias representadas por limos, grabas y arcillas, que cubren el 48,3\% del municipio; rocas carbonatadas entre las que se destacan las calizas de diversos tipos, margas calcáreas y dolomitas entre otras, en un 25,7\%; rocas de composición terrígenas constituidas por areniscas, limonitas, arcillas entre otras, en un 11,6\%, y rocas ígneas intrusivas representadas por serpentinas y gabros, en un $15,7 \%$. Las rocas efusivas aparecen en un $0,4 \%$, constituidas por diabasas, lavobrechas, tobas y basaltos.

Posee cuatro regiones bien diferenciadas. La llanura norte que se extiende por más de $60 \mathrm{~km}$, con suelos de deficiente drenaje, dedicada fundamentalmente a la actividad pecuaria, y con una costa baja acumulativa en la que existen humedales y lagunas costeras; las alturas calizas que ocupan la faja central del municipio y se extienden de este a oeste, están compuestas por las sierras de Bamburanao, Meneses, Jatibonico y La Canoa, con una altura máxima de $412 \mathrm{~m}$, con suelos pobres y alto afloramiento rocoso, uso pecuario, forestal y cultivos varios con algunas áreas de caña; la llanura alta, hacia el sur, donde nacen los ríos Jatibonico del Norte y Jatibonico del Sur y el Caonao, con un relieve ondulado y suelos de gran fertilidad con uso pecuario y cultivos varios y, por último, el territorio marino que se encuentra representado por la bahía de Buenavista, con una extensión de 460,69 $\mathrm{km}^{2}$ y profundidades hasta de $4 \mathrm{~m}$, entre sus accidentes geográficos más significativos se encuentran la propia bahía de Buenavista, las playas Carbó, Vitoria, Júcaro y Bofill; las ensenadas y esteros de Yaguajay, Juncal, Cristóbal, los Robles, los Jacos, las Palmas, Guayarúes, boca de Salinas, estero Real y boca del Róbalo; las puntas de Coscorrones, Guajiro, Obispo y Tablosa.

El clima es tropical húmedo con abundantes precipitaciones, la temperatura media anual es de $24^{\circ} \mathrm{C}$ y en el verano puede subir a más de $36^{\circ} \mathrm{C}$, resultando además intere- 
santes los reportes de escarcha en los años 1841-1888-1901 y 1940 y el paso de más de 30 ciclones con mayor incidencia en los meses de septiembre, octubre y noviembre.

Los ríos más caudalosos son el Jatibonico del Norte, que nace al sur del municipio y descarga sus aguas en la costa norte, sirviendo de frontera con la provincia de Ciego de Ávila; el Jatibonico del Sur, que desemboca en la costa sur de la provincia; el CaOnao, afluente del Zaza, que atraviesa la porción sur del territorio de este a oeste y el Máximo, que nace en las lomas de Meneses y atraviesa el pueblo de Yaguajay y el Batey de Vitoria.

Las corrientes marinas en la plataforma se originan fundamentalmente por la acción del viento y la marea, la circulación resultante indica una deriva hacia el NW. La marea es semidiurna. Después de la construcción del pedraplén de Caibarién-Cayo Santa María la salinidad se mantiene elevada. Según el agrupamiento predominan los suelos pardos sialíticos, que ocupan la mayor parte del territorio, con una superficie de 346,23 $\mathrm{km}^{2}$, lo que representa un $33,13 \%$.

La flora terrestre es muy rica y diversificada. Prevalecen los bosques de manglar y los bosques semideciduos en los cayos, costas y áreas de tierra firme; la vegetación de sabanas y bosques de galerías, con diferente grado de conservación, a lo largo de los cauces fluviales. La vegetación cultural se relaciona con las actividades socioeconómicas. El municipio cuenta con el 15,6\% de la superficie cubierta de árboles, perteneciendo el 1,6\% a los cayos de piedra donde existen 94 ha de bosques semideciduos y de manglar.

Las áreas protegidas, por el Acuerdo 4262 de fecha 14-12-2001, del Consejo de Ministros son: el Parque Nacional Caguanes, con extensión de 20 432,23 ha y el Área Protegida de Recursos Manejados Jobo Rosado, con extensión de 4181 ha. Los Elementos Naturales Destacados, que se encuentran en fase de aprobación por el SNAP son: La Chucha, con extensión de 233 ha; Boquerones, con extensión de 3190 ha y Tasajera, con 2 048 ha. Con la categoría de Área Protegida de Recursos Manejados se encuentra aprobada la Reserva de la Biósfera Bahía de Buenavista, con los núcleos: Parque Nacional Caguanes y los Elementos Naturales Destacados "La Chucha", "Boquerones" y "Tasajera".

La población, según la Oficina Nacional de Estadísticas e Información en el 2010 (ONEI, 2011b), residía en 69 asentamientos que agrupaban el 97,7\% de la población. De ellos, 12 clasifican como urbanos y concentran el 65,3\% de los habitantes. El total de población, en el 2010, era de 56467 con 20517 viviendas y una densidad de 54,10 hab/km².

Se ha caracterizado por la disminución de la población, en los últimos años, con una tasa de crecimiento medio anual de 6,29 personas por cada mil. El núcleo cabecera es el poblado urbano de primer orden de Yagüajay, con una población de más 10000 habitantes. Cercano al mismo están los antiguos bateyes azucareros de Narcisa y Vitoria, considerados como núcleos urbanos independientes. Se destacan en importancia los núcleos urbanos de Mayajigua, Meneses, Iguará, Jarahueca y Venegas. 
Las principales actividades se centran en la agricultura no cañera, contando con una Empresa Agropecuaria y tres Granjas Agroindustriales, derivadas de la reestructuración del AzCuba; una Empresa de cultivos varios y una Pecuaria. Además, en la subordinación local existe una empresa de Comercio y Gastronomía y dos Unidades Básicas Económicas, así como seis unidades presupuestadas y un grupo de establecimientos provinciales. En el sector cooperativo existen 11 UBPC del AzCuba, una de cultivos varios, cinco de pecuaria y una apícola.

Del $68,8 \%$ de la superficie agrícola el 31,5\% está ocupada por cultivos permanentes, pastos y forrajes y frutales; los temporales, con el 13,0\%, están representados por los cultivos varios y el arroz. El área ociosa ocupa el 5,4\%.La tenencia de la tierra tiene un predominio del sector no estatal, representada por los campesinos independientes y las UBPC, con el 50\% y 20\%, respectivamente.

Fueron identificadas 13 UP de primer orden (12 terrestres y una marina) y 57 de segundo orden ( 54 terrestres y tres marinas) (Martín, Salinas, Martínez, Olivera, et al., 2012) (Tabla 2 y Figura 4).

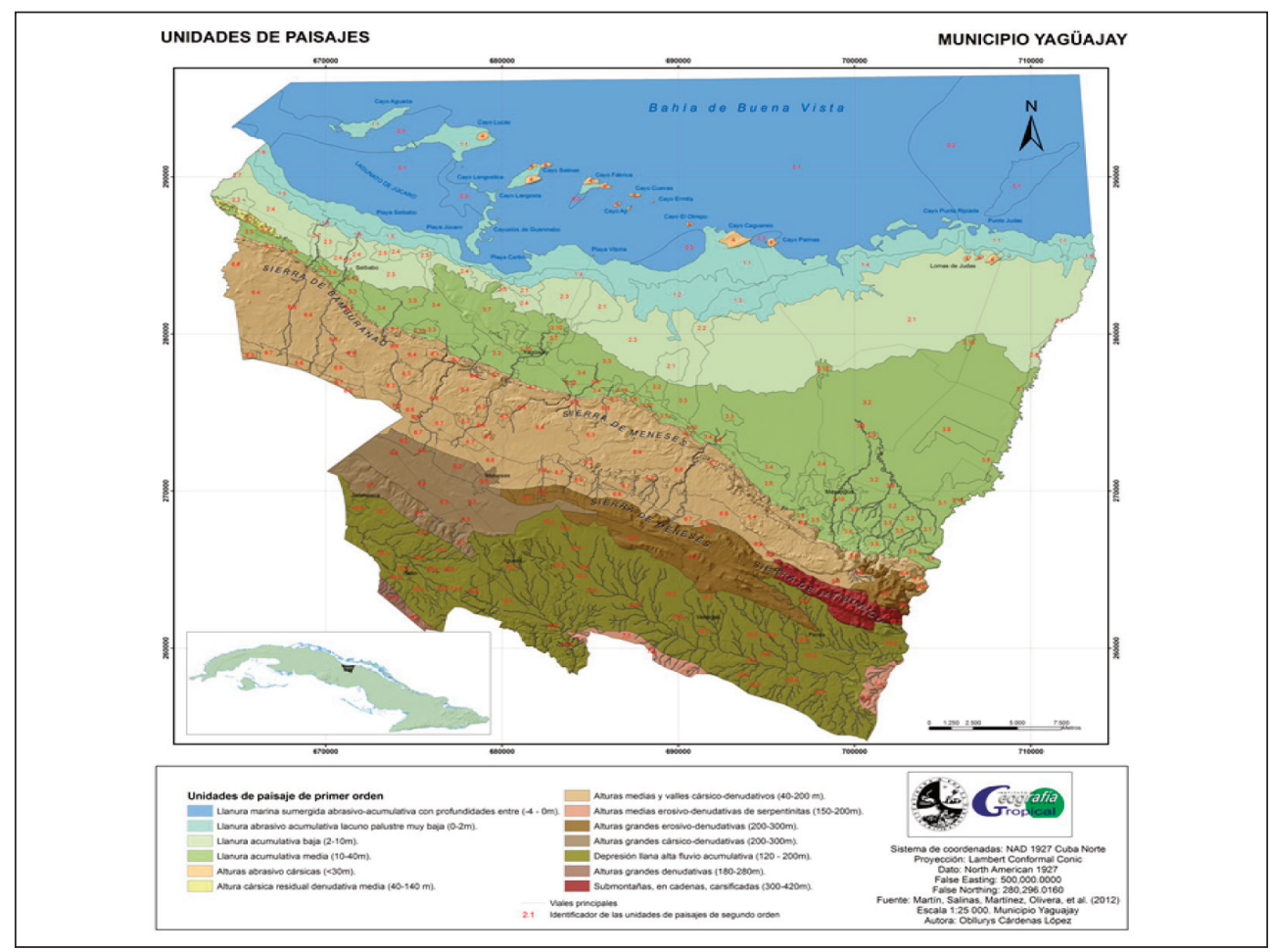

Figura 4. Unidades de paisaje del municipio Yagüajay. 
Tabla 2. Unidades de paisaje del municipio Yagüajay

\begin{tabular}{|c|c|}
\hline$U P$ & Descripción \\
\hline $\mathrm{m}$ & $\begin{array}{l}\text { Llanura marina sumergida abrasivo-acumulativa con profundidades hasta } 4 \mathrm{~m} \text {, sobre } \\
\text { arena carbonatada }\end{array}$ \\
\hline 0.1 & Llanura sumergida con fondo fango-arenoso con fanerógamas por partes \\
\hline 0.2 & Llanura sumergida con fondo fangoso con fanerógamas por partes \\
\hline 0.3 & Llanura sumergida con fondo arenoso sin vegetación \\
\hline 1 & $\begin{array}{l}\text { Llanura abrasivo acumulativa lacuno palustre muy baja }(0-2 \mathrm{~m}) \text { sobre depósitos limo- } \\
\text { arenosos-arcillosos }\end{array}$ \\
\hline 1.1 & Superficie plana $\left(<1^{\circ}\right)$ con suelo halomórfico salino permanentemente inundado y mangle \\
\hline 1.2 & $\begin{array}{l}\text { Superficie plana }\left(<1^{\circ}\right) \text { con suelo halomórfico salino estacionalmente inundado, con her- } \\
\text { bazal de ciénaga }\end{array}$ \\
\hline 1.3 & $\begin{array}{l}\text { Superficie plana }\left(<1^{\circ}\right) \text { con suelo halomórfico salino y bosque natural degradado, her- } \\
\text { bazal de ciénaga y pastos naturales }\end{array}$ \\
\hline 1.4 & Superficie plana $\left(<1^{\circ}\right)$ con suelo gley vértico, pastos naturales y cultivos varios \\
\hline 1.5 & $\begin{array}{l}\text { Superficie plana }\left(<1^{\circ}\right) \text { con suelo ferralítico amarillento con bosques naturales, pastos } \\
\text { naturales y cultivos varios }\end{array}$ \\
\hline 1.6 & $\begin{array}{l}\text { Cauce y el plano de inundación en forma de cubeta con pastos y restos de bosques de } \\
\text { galería }\end{array}$ \\
\hline 2 & Llanura acumulativa baja $(2-10 \mathrm{~m})$ sobre depósitos limo-arenosos-arcillosos \\
\hline 2.1 & Superficie plana $\left(<1^{\circ}\right)$ con suelo gley vértico, pastos naturales y cultivos varios \\
\hline 2.2 & Superficie plana $\left(<1^{\circ}\right)$ con suelo halomórfico salino, pastos naturales y cultivos varios \\
\hline 2.3 & $\begin{array}{l}\text { Superficie plana }\left(<1^{\circ}\right) \text { con suelo ferralítico amarillento, cultivos varios, pastos y bos- } \\
\text { ques naturales }\end{array}$ \\
\hline 2.4 & $\begin{array}{l}\text { Superficie plana }\left(<1^{\circ}\right) \text { con suelo húmico calcimórfico y pardo, cultivos varios y pastos } \\
\text { naturales }\end{array}$ \\
\hline 2.5 & Superficie plana $\left(<1^{\circ}\right)$ con suelo gley nodular ferruginoso y bosques de ciénaga \\
\hline 2.6 & Superficie plana $\left(<1^{\circ}\right)$ con suelo fluvisol y cultivos varios \\
\hline 2.7 & $\begin{array}{l}\text { Cauce y del plano de inundación en forma de cubeta con suelo fluvisol, pastos y res- } \\
\text { tos de bosques de galería }\end{array}$ \\
\hline 3 & $\begin{array}{l}\text { Llanura acumulativa media }(10-40 \mathrm{~m}) \text { sobre depósitos limo- arenosos-arcillosos, caliza, } \\
\text { margas y grava fina. }\end{array}$ \\
\hline 3.1 & Superficie plana $\left(<1^{\circ}\right)$ con suelo fluvisol y cultivos varios \\
\hline 3.2 & Superficie plana $\left(<1^{\circ}\right)$ con suelo gley vértico, cultivos varios y pastos naturales \\
\hline
\end{tabular}




\begin{tabular}{|c|c|}
\hline$U P$ & Descripción \\
\hline 3.3 & Superficie plana $\left(<1^{\circ}\right)$ con suelo ferralítico amarillento, cultivos varios y pastos naturales \\
\hline 3.4 & $\begin{array}{l}\text { Superficie plana }\left(<1^{\circ}\right) \text { con suelo pardo y húmico calcimórfico, cultivos varios y bos- } \\
\text { ques degradados }\end{array}$ \\
\hline 3.5 & Superficie plana $\left(<1^{\circ}\right)$ con suelo pardo, cultivos varios, frutales y pastos naturales \\
\hline 3.6 & Superficie plana $\left(<1^{\circ}\right)$ con suelo ferralítico amarillento, cultivos varios y pastos naturales \\
\hline 3.7 & Superficie ondulada $\left(1-3^{\circ}\right)$ con colinas residuales aisladas con suelo pardo y cultivos varios \\
\hline 3.8 & $\begin{array}{l}\text { Cauce y del plano de inundación en forma de cubeta con suelo fluvisol y con pastos } \\
\text { y restos de bosques de galería }\end{array}$ \\
\hline 3.9 & Superficie plana $\left(<1^{\circ}\right)$ con el embalse Aridanes y vegetación acuática \\
\hline 3.10 & $\begin{array}{l}\text { Superficie plana }\left(<1^{\circ}\right) \text { con los asentamientos poblacionales: Yagüajay, Nela, Narcisa, Vi- } \\
\text { toria, Mayajigua, Caserío Caliene, Obdulio Morales, Seibabo. Centeno, Aridanes y El Río }\end{array}$ \\
\hline 4 & Alturas abrasivo-cársicas $(<30 \mathrm{~m})$ sobre rocas carbonatadas \\
\hline 5 & $\begin{array}{l}\text { Alturas cársicas residuales denudativas }(40-140 \mathrm{~m}) \text { sobre calizas dolomitizadas y bio- } \\
\text { calcarenitas }\end{array}$ \\
\hline 5.1 & $\begin{array}{l}\text { Superficie inclinada y medianamente inclinada }\left(5-15^{\circ}\right) \text { con suelo fersialítico pardo ro- } \\
\text { jizo y bosques semideciduos micrófilos }\end{array}$ \\
\hline 5.2 & $\begin{array}{l}\text { Superficie plana }\left(<1^{\circ}\right) \text { con suelo fersialítico pardo rojizo y bosques semideciduos mi- } \\
\text { crófilos }\end{array}$ \\
\hline 6 & Alturas y valles cársico-denudativos $(40-200 \mathrm{~m})$ sobre rocas calizas \\
\hline 6.1 & $\begin{array}{l}\text { Escarpe inclinado y muy inclinado }\left(5-35^{\circ}\right) \text { con suelo pardo y restos de bosques semi- } \\
\text { deciduos y pastos naturales }\end{array}$ \\
\hline 6.2 & $\begin{array}{l}\text { Cadena de colinas residuales inclinadas }\left(5-10^{\circ}\right) \text { con suelos pardos sialíticos y fersialí- } \\
\text { tico pardo rojizo y bosques semideciduos }\end{array}$ \\
\hline 6.3 & $\begin{array}{l}\text { Superficie suavemente inclinada }\left(3-5^{\circ}\right) \text { con suelos pardos sialíticos y bosques semide- } \\
\text { ciduos mesófilo poco degradados }\end{array}$ \\
\hline 6.4 & $\begin{array}{l}\text { Superficie suavemente inclinada }\left(3-5^{\circ}\right) \text { con suelo fersialítico pardo rojizo, bosques se- } \\
\text { mideciduos mesófilos medianamente degradados y focos de pastos naturales }\end{array}$ \\
\hline 6.5 & Superficie ondulada $\left(1-3^{\circ}\right)$ con suelo ferralítico, matorrales y pastos naturales \\
\hline 6.6 & $\begin{array}{l}\text { Superficie ondulada }\left(1-3^{\circ}\right) \text { con suelos pardos sialíticos y húmicos calcimórfico, cultivos } \\
\text { varios y pastos naturales }\end{array}$ \\
\hline 6.7 & $\begin{array}{l}\text { Superficie ondulada }\left(1-3^{\circ}\right) \text { con suelo fersialítico pardo rojizo, cultivos varios y pastos } \\
\text { naturales }\end{array}$ \\
\hline 6.8 & $\begin{array}{l}\text { Cauce y de las cañadas erosivas en forma de } \mathrm{V} \text { con suelo fluvisol y restos de bosque } \\
\text { de galería }\end{array}$ \\
\hline
\end{tabular}




\begin{tabular}{|c|c|}
\hline$U P$ & Descripción \\
\hline 6.9 & $\begin{array}{l}\text { Superficie ondulada }\left(1-3^{\circ}\right) \text { con los asentamientos poblacionales de Jobo Rosado y } \\
\text { Juan Francisco }\end{array}$ \\
\hline 7 & $\begin{array}{l}\text { Alturas erosivo-denudativas de serpentinitas }(150-200 \mathrm{~m}) \text { sobre rocas ultramafitas ser- } \\
\text { pentinizadas y gabros. }\end{array}$ \\
\hline 7.1 & $\begin{array}{l}\text { Superficie ondulada }\left(1-3^{\circ}\right) \text { con suelo fersialítico pardo rojizo cubierto por restos de cua- } \\
\text { bal degradado, plantaciones forestales y pastos naturales }\end{array}$ \\
\hline 7.2 & $\begin{array}{l}\text { Cañada erosivo-acumulativa en forma de } \mathrm{V} \text {, con suelo fluvisol y restos de bosques de } \\
\text { galería y pastos }\end{array}$ \\
\hline 8 & $\begin{array}{l}\text { Alturas erosivo-denudativas ( } 200-300 \mathrm{~m} \text { ), se desarrollan sobre calizas, arcillas, brechas } \\
\text { y conglomerados }\end{array}$ \\
\hline 8.1 & $\begin{array}{l}\text { Superficie medianamente inclinada }\left(10-15^{\circ}\right) \text { con suelo pardo, bosques semideciduos de- } \\
\text { gradados y restos de pastos naturales }\end{array}$ \\
\hline 8.2 & $\begin{array}{l}\text { Superficie suavemente inclinada }\left(3-5^{\circ}\right) \text { con suelo pardo con cultivos varios, pastos na- } \\
\text { turales y resto de bosque semideciduo muy degradado }\end{array}$ \\
\hline 8.3 & $\begin{array}{l}\text { Superficie suavemente inclinada }\left(3-5^{\circ}\right) \text { con suelo fersialítico pardo rojizo con cultivos } \\
\text { varios, pastos naturales y resto de bosque semideciduo muy degradado }\end{array}$ \\
\hline 8.4 & Cauce encajado en forma de $\mathrm{V}$ con suelo fluvisol y bosque de galería degradado \\
\hline 9 & $\begin{array}{l}\text { Alturas cársico-denudativas (200-300 m) sobre rocas calizas, arcillas, brechas y conglo- } \\
\text { merado }\end{array}$ \\
\hline 9.1 & $\begin{array}{l}\text { Superficie suavemente inclinada diseccionada }\left(3-5^{\circ}\right) \text { con suelo fersialítico pardo rojizo, } \\
\text { cultivos varios y pastos naturales }\end{array}$ \\
\hline 9.2 & $\begin{array}{l}\text { Superficie ondulada }\left(1-3^{\circ}\right) \text { con suelos fersialíticos y pardos sialíticos, cultivos varios, pas- } \\
\text { tos naturales y restos de bosque semideciduo degradado }\end{array}$ \\
\hline 9.3 & Superficie plana $\left(<1^{\circ}\right)$ con suelo ferralítico rojo, cultivos varios y pastos naturales \\
\hline 9.4 & $\begin{array}{l}\text { Cañadas cársico-erosivas de fondo plano en formas de cubetas con suelo fluvisol y pas- } \\
\text { tos y restos de bosque semideciduo degradado }\end{array}$ \\
\hline 9.5 & Superficie plana $\left(<1^{\circ}\right)$ y ondulada $\left(1-3^{\circ}\right)$ con el asentamientos Meneses \\
\hline 10 & $\begin{array}{l}\text { Depresión llana fluvio-acumulativa }(120-200 \mathrm{~m}) \text {, sobre rocas ultramafitas serpentiniza- } \\
\text { das, gabros, diabasas y dioritas }\end{array}$ \\
\hline 10.1 & $\begin{array}{l}\text { Superficie ondulada }\left(1-3^{\circ}\right) \text { con suelo pardo con cultivos varios, pastos naturales, fruta- } \\
\text { les, plantaciones forestales y restos de matorral espinoso degradado }\end{array}$ \\
\hline 10.2 & Superficie ondulada $\left(1-3^{\circ}\right)$ con suelo pardo, pastos naturales y cultivos varios \\
\hline 10.3 & $\begin{array}{l}\text { Cauce y las cañadas en forma de } \mathrm{V} \text {, con suelo fluvisol y restos de bosques en galería y } \\
\text { pastos }\end{array}$ \\
\hline
\end{tabular}




\begin{tabular}{|c|c|}
\hline$U P$ & Descripción \\
\hline 10.4 & Superficie ondulada $\left(1-3^{\circ}\right)$ con embalses y vegetación acuática y matorrales \\
\hline 10.5 & $\begin{array}{l}\text { Superficie ondulada }\left(1-3^{\circ}\right) \text { con los asentamientos poblacionales: Jarahueca, Venegas, } \\
\text { Perea, Itabo, Iguará, la Comunidad de Pueblo Nuevo, Piñero y La Dalia }\end{array}$ \\
\hline 11 & Alturas denudativas $(180-280 \mathrm{~m})$ sobre granodioritas, lulitas y arcillas \\
\hline 11.1 & Superficie suavemente inclinada $\left(3-5^{\circ}\right)$ con suelo pardo, pastos naturales y cultivos varios \\
\hline 11.2 & $\begin{array}{l}\text { Cañada erosivo-acumulativa en forma de } \mathrm{V} \text {, con suelo fluvisol y restos de bosques de } \\
\text { galería y pastos }\end{array}$ \\
\hline 12 & $\begin{array}{l}\text { Montañas en cadenas, carsificadas }(300-420 \mathrm{~m}) \text {, sobre brechas, conglomerados, calca- } \\
\text { renitas, margas y calizas }\end{array}$ \\
\hline 12.1 & $\begin{array}{l}\text { Montañas en cadenas medianamente inclinadas }\left(10^{\circ}-15^{\circ}\right) \text {, con suelos pardos sialíticos } \\
\text { con bosques semideciduos degradados }\end{array}$ \\
\hline 12.2 & $\begin{array}{l}\text { Cauce encajado en forma de } \mathrm{V} \text { con suelo fluvisol y bosque en galería medianamente } \\
\text { degradado }\end{array}$ \\
\hline
\end{tabular}

Fuente: Elaborado por la autora a partir de Martín, Salinas, Martínez, Olivera, et al., 2012.

De las UP terrestres identificadas para el territorio nacional, tres aparecen en el municipio: las llanuras secas y medianamente secas, las llanuras medianamente húmedas y las depresiones intermontañosas, colinas, alturas y montañas bajas húmedas, que están influenciadas por el basamento geológico, la altura y la distancia del mar. La exposición de las alturas y valles interiores condicionan la existencia de cambios en el suelo y en la vegetación, como consecuencia de las variaciones en el humedecimiento y la insolación. La UP marina se corresponde con la llanura marina abrasivo-acumulativa sobre depósitos de arena carbonatada y fango, hasta los $4 \mathrm{~m}$.

Entre las UP disponibles a ser utilizadas sin grandes restricciones, que clasifican poco sensibles, se encuentran la 3, 6 y 9; las disponibles a ser utilizadas con algunas restricciones, que clasifican como medianamente sensibles son la 2, 7 y 10. Las UP con grandes restricciones para su uso, que clasifican como muy sensibles, son la 1, 4, 5, 8, 11 y $12 \mathrm{y}$, por sus peculiaridades dentro de estas, las de segundo orden son: 1.6, 2.7, $3.8,6.1,6.2,6.8,7.2,8.4,9.4$ y 10.3 .

\subsubsection{Identificación de las limitaciones ambientales de uso}

Entre las limitaciones más significativas de la UPm se encuentran la protección legal de los recursos que en ella existen y el estado de deterioro en que se encuentran los ecosistemas. En las unidades costeras la temporada lluviosa trae consigo penetra- 
ciones del mar que afectan su infraestructura y su población, además, los territorios bajos quedan expuestos a inundaciones por el desbordamiento de los cauces, afectándose las infraestructuras y población asentada, las áreas agrícolas y la masa ganadera. Entre las causas que provocan esta situación se encuentran el establecimiento de viviendas, instalaciones y cultivos en las zonas de inundación de los ríos, la poca profundidad de los cauces, la inexistencia de la faja forestal hidrorreguladora y la poca capacidad de las infraestructuras para asimilar la crecida. Los deslizamientos de tierra, frecuentes en la citada temporada, ocurren en sitios de fuertes pendientes.

La UPm se encuentra limitada por la legislación ambiental y por el deterioro de sus ecosistemas. En la UP 1 las limitaciones fundamentales están relacionadas con el aumento del nivel medio del mar calculado en diferentes escenarios; por las penetraciones del mar; por la presencia de suelos salinizados y por la presencia de algún tipo de protección legal relacionada con la zona costera y la existencia del área protegida, además, clasifica como muy sensible. La 2 es similar a la 4, en cuanto a la existencia de áreas protegidas; los suelos se encuentran salinizados y existe el riesgo de inundaciones marinas y fluviales. En la 3 existe peligro de inundaciones fluviales y se encuentra establecida la protección a las fajas forestales hidrorreguladoras de ríos, embalses, canales y del patrimonio construido, además, los suelos poseen diferentes grados de salinización y de pedregosidad. La 4, además, clasifica como muy sensible.

En las UP 5, 6, 8 y 12 predominan los hundimientos cársicos y los deslizamientos de tierra, además, se encuentra establecida la protección de sus valores naturales, de las fajas forestales hidrorreguladoras de ríos, embalses y del patrimonio construido. Las UP 5, 8 y 12, clasifican como muy sensibles. En la 7 existen limitaciones por la protección de las fajas forestales hidrorreguladoras de los ríos, por la erosión de los suelos y la pedregosidad. En la 9, 10 y 11 las limitaciones se corresponden con la protección de los suelos de buena capacidad agroproductiva, con la protección de las fajas forestales hidrorreguladoras de ríos, embalses, del patrimonio construido y con la existencia de suelos pedregosos y erosionados, la 11 clasifica como muy sensible.

\subsubsection{Identificación del uso potencial}

En la UPm predomina el uso potencial de conservación; en la UP 1, el uso potencial de conservación, el turístico y el forestal de protección; en la 2, el pecuario, el de conservación y el forestal de protección de la zona costera; en la UP 3, el agrícola y el pecuario; en la 4, el de conservación y el de turismo; en la 5, el de conservación, el de turismo y el forestal; en la 6, el de conservación, el agrícola y el pecuario; en la 7 , el de conservación y el forestal; en la 8, el pecuario y el agrícola; en la 9, el agrícola y el pecuario; en la 10, el agrícola, el hídrico y el de conservación; en las UP 11 y 12 predomina el uso potencial de conservación. 


\subsubsection{Identificación de la compatibilidad de uso}

Se puso de evidencia la sobreexplotación y la subutilización de los recursos y la existencia de conflictos entre los sectores socioeconómicos que coexisten en el territorio, por la intervención no controlada en el espacio de otro sector. Estas situaciones tienen como causas fundamentales el incumplimiento de la legislación ambiental vigente; la falta de recursos para poner a producir las tierras ociosas; la falta de contabilización de las tierras ociosas; la inexistencia de límites físicos en las área de conservación de la flora y la fauna; el empleo de técnicas rudimentarias, a la hora de utilizar los recursos; la indolencia y falta de control de los tenentes y la poca comunicación entre ellos.

En la UPm la incompatibilidad de uso tiene que ver con el empleo de artes de pesca rudimentarias, utilizadas por los pescadores en territorio del área protegida de Caguanes, sobreexplotando los fondos frágiles, sometiéndolos a la degradación y a la pérdida de los ecosistemas.

Cuando existe conflicto entre sectores, por lo general, se pone de manifiesto la sobrexplotación de los recursos, tal es el caso de la 1.1 y 1.2, entre los sectores pecuario, turístico y de conservación; 1.3 y 8.1, entre los sectores pecuario y de conservación; 2.4, 3.3, 3.4, 7.1 y 9.3, entre los sectores pecuario y agrícola; 1.4, 1.5, 9.1 y 9.2, entre los sectores pecuario, agrícola y forestal; 2.1, 2.2, 2.3 y 6.4, entre los sectores pecuario, agrícola y de conservación y en la 6.5 , entre los sectores pecuario y forestal. En la 1.6, 2.7, 3.8, 6.8, 7.2, 8.4, 9.4, 10.3 y 10.4 existen conflictos entre el uso actual y lo dispuesto en la legislación ambiental, principalmente referido al incumplimiento de la protección de las fajas forestales hidrorreguladoras de cauces fluviales y embalses.

Con uso actual acorde a sus potencialidades se encuentran las UP 2.5, 2.6, 3.1, 3.2, 3.5, 3.6, 3.7, 3.9, 3.10, 4, 5.1, 5.2, 6.1, 6.2, 6.3, 6.6, 6.7, 6.9, 9.5. 10.1, 10.2, 10.5, 11.1, $11.2,12.1$ y 12.2 .

\subsubsection{Identificación de la problemática ambiental}

- La contaminación de las aguas marinas, provocada por la desembocadura del cauce contaminado del río Guaní, perteneciente a la provincia de Villa Clara (UPm).

- El aumento de la salinidad de las aguas marinas, provocada por el poco intercambio del agua dulce y salada debido a la canalización de los cauces, a la obstrucción de los drenajes naturales y a la existencia del pedraplén de CaibariénCayo Santa María (UPm).

- La degradación del hábitat del fondo marino, la disminución de las poblaciones marinas y la afectación económica a los pobladores que dependen de los productos marinos, provocada por el uso inadecuado de las artes de pesca (UPm). 
- La degradación del manglar, provocada por la tala indiscriminada y por la permanencia incontrolada del ganado (UP 1 y 2).

- Las afectaciones a la población por penetraciones del mar, provocadas por eventos hidrometeorológicos extremos (UP 1, 2 y 4, fundamentalmente)

- La salinización de los suelos (UP 1, 2, 3) y su erosión (UP 5, 6, 7, 8, 9, 10, 11, 12), provocadas por el exceso de fertilización química, por el avance de la intrusión marina, por el empleo de aguas de mala calidad en el riego, por la falta de rotación de cultivos y por la insuficiente aplicación de medidas antierosivas, fundamentalmente.

- La contaminación de los pozos de abasto de agua y de los cauces fluviales superficiales (en todas las UP), provocada por la degradación de las fajas forestales de protección, la sobreexplotación de los acuíferos, el vertimiento de líquidos y sólidos provenientes de los asentamientos e instalaciones, fundamentalmente.

- La pérdida de la biodiversidad y la fragmentación de los corredores biológicos en los biocentros de importancia (en todas las UP, fundamentalmente en la 1, 4, 5, 6 y 7), provocada por la tala ilícita y por el aumento de las áreas agrícola y ganaderas.

- La degradación de las fajas forestales de protección de los cauces fluviales superficiales y embalses (en todas las UP), provocada por la tala ilícita y el aumento de las áreas agrícolas y ganaderas.

- La pérdida de los valores patrimoniales (UP 1, 3.10, 6.9 y 10.5), provocada por la falta de recursos para la rehabilitación de los sitios, monumentos, infraestructuras y por la poca conciencia ambiental de pobladores y visitantes.

- El mal estado de la infraestructura, redes y del fondo habitacional en los asentamientos y zonas habitadas (UP 1, 3.10, 6.9 y 10.5), provocado por la falta de recursos para su rehabilitación y reposición.

- La pérdida de la calidad del agua, del aire y del suelo por la existencia de focos contaminantes (UP 3.10, 6.9 y 10.5), provocada por la utilización de tecnologías obsoletas, la escasez de piezas de repuesto y la falta de sistemas de tratamiento de residuales en fábricas, instalaciones y asentamientos. 


\subsubsection{Conformación del modelo de ordenamiento ambiental}

En la UPm la política ambiental de protección y conservación está dirigida a mantener los servicios ambientales que brindan los biotopos existentes.

En la UP 1 prevalece la política ambiental de protección y conservación dirigida a mantener sus altos valores ambientales y los servicios ambientales que brinda a la naturaleza y a la sociedad. El uso principal recomendado, más extendido, es el de conservación y el secundario es el turismo de naturaleza y el de conservación. Es de destacar que esta UP es muy sensible y, unido a la UP 2, son las más vulnerables a los eventos hidrometeorológicos extremos y a los escenarios de variabilidad climática, por inundaciones costeras.

En la UP 2 la política de aprovechamiento, con uso recomendado pecuario expresa la capacidad de la UP para el desarrollo de esta actividad, con limitaciones para el desarrollo de los cultivos y con atención a su sensibilidad media y a su alta vulnerabilidad ante eventos hidrometeorológicos. La política de protección y conservación se dicta sobre los valores naturales existentes y la de restauración para asegurar la permanencia de los servicios ambientales que brindan sus ecosistemas.

En la UP 3 predomina la política de aprovechamiento, con uso recomendado agrícola, avalando el alto potencial de la misma para el desarrollo de esta actividad. La restauración está presente por la existencia de problemas ambientales.

En las UP 4, 5 y 6 está presente la política de protección y conservación, con uso recomendado de conservación y turismo de naturaleza. Especial atención reviste la alta sensibilidad de la 4 y 5 . En la 6 , además, y en la 7 y 8 , se propone la política de restauración para revertir el estado desfavorable que presentan los recursos y para que sean utilizados de forma óptima, de acuerdo a sus potenciales.

En las UP 9 y 10 predominan las políticas de aprovechamiento y restauración para el desarrollo de la actividad agrícola y pecuaria. Estas dependen de la restauración a las condiciones óptimas para su buen desarrollo y responden a sus limitaciones naturales.

En las UP 11 y 12 se propone la política protección y conservación debido a su alta sensibilidad y con vistas a mantener y asegurar los servicios ambientales que proporcionan y la de restauración para recuperar y enriquecer el recurso forestal.

En la Figura siguiente aparece la representación de las propuestas realizadas para las UA del municipio. 


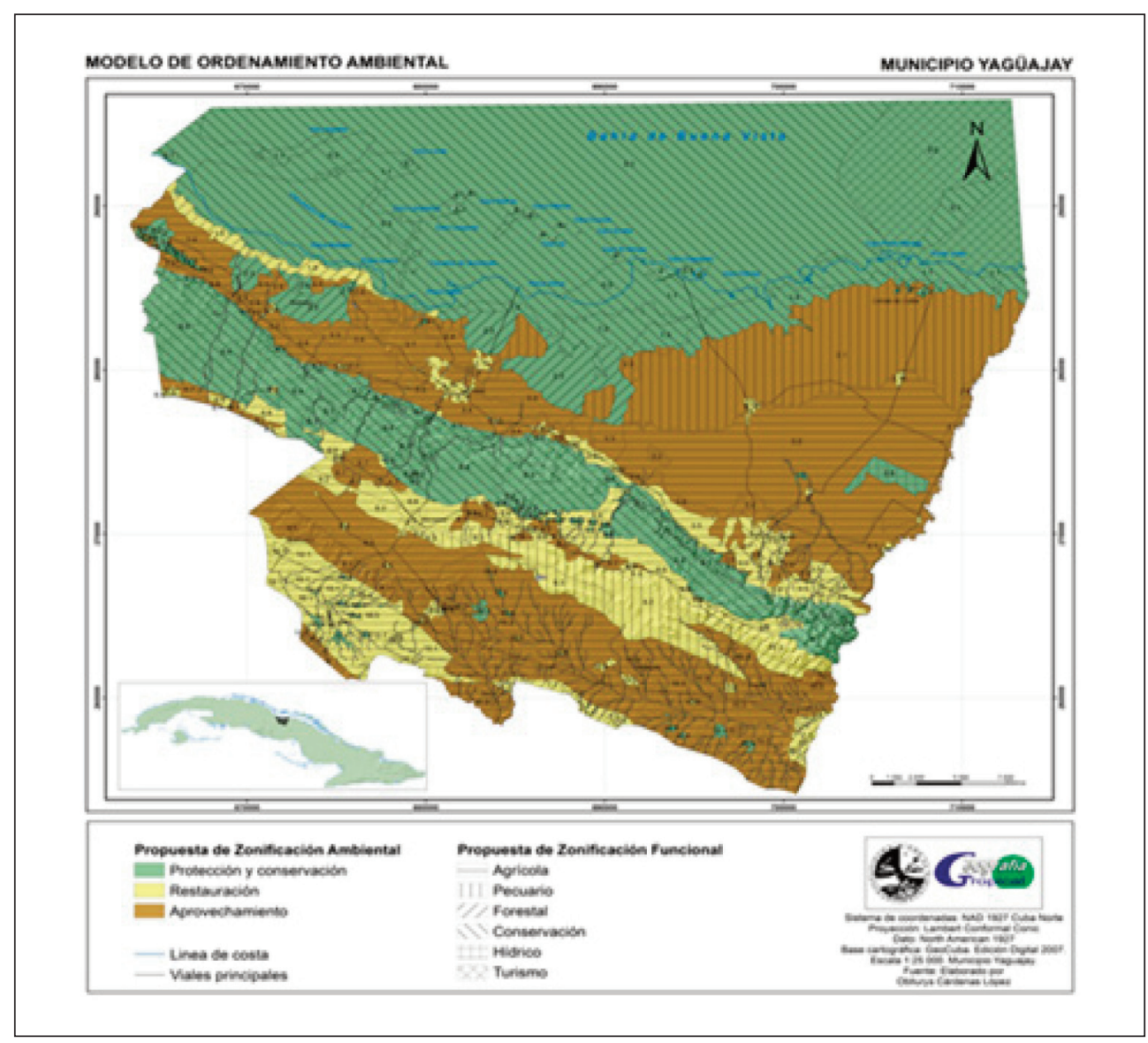

Figura 5. Modelo de ordenamiento ambiental del municipio Yagüajay.

\subsubsection{Interacción con el proceso de ordenamiento territorial}

Una vez aprobado el MOA, en el taller participativo, fue presentado, debatido y aprobado en el Consejo de Administración Municipal y en la Asamblea Municipal del Poder Popular, en Acuerdo 202 del año 2013. Las instancias planificadoras territoriales se encuentran en la fase de inserción de las propuestas al proceso de ordenamiento territorial. El CITMA monitoreará el proceso y realizará las correcciones y adecuaciones necesarias. 


\section{Conclusiones}

1. Internacionalmente existe gran diversidad de conceptos y enfoques al abordar el ordenamiento territorial y el ambiental, tanto en el orden académico, científico, como legal. A estos se adecuan procedimientos metodológicos diversos, aunque con etapas o fases de trabajo similares. Las experiencias nacionales y las condiciones específicas de evolución del ordenamiento territorial y de la gestión ambiental, constituyen los factores fundamentales en la definición de las bases teóricas y metodológicas para el proceso de ordenamiento ambiental en Cuba, tales como: definición del paisaje como sistema ambiental de base, empleo del enfoque participativo, establecimiento de cinco fases de trabajo y la identificación de tres escalas territoriales.

2. El sistema ambiental de análisis más apropiado para el proceso de ordenamiento ambiental es el paisaje, dada su conceptualización teórica y metodológica, tanto internacional como nacional, que ha permitido reconocer su carácter integral, existencia objetiva y la posibilidad de diferenciar su manifestación en diversas escalas de análisis: nacional, regional y local.

3. El enfoque participativo, llevado a cabo mediante el intercambio entre los especialistas y los actores territoriales durante todas las fases de trabajo, en los talleres de expertos y participativos y en los recorridos de campo, propició la apropiación de los conocimientos locales por parte del equipo de trabajo, la toma de decisiones consensuadas, el completamiento y actualización de la información y la capacitación, compromiso y apropiación de los resultados de todos los involucrados.

4. El procedimiento metodológico propuesto ofrece pautas que han de utilizarse en dependencia del territorio en que se trabaje, de los objetivos, de los recursos disponibles y de la información que se logre obtener. El mismo contribuye al cumplimiento de las metas y acciones definidas en la Ley 81 de Medio Ambiente y en las Estrategias Ambientales Nacionales de Cuba, en relación con el ordenamiento ambiental, al aportar como resultado final un modelo que supera las barreras metodológicas que impedían la articulación entre el ordenamiento territorial y el ordenamiento ambiental. En cada fase de trabajo se señalan elementos metodológicos y criterios de análisis que poseen orden lógico de intervención e interrelación.

5. El modelo de ordenamiento ambiental, como insumo activo y consistente para la incorporación de la dimensión ambiental en el proceso de ordenamiento territorial y como producto informativo para las autoridades ambientales aporta propuestas diferenciadas por cada sistema ambiental y por los sectores socioeconómicos, identificados en el territorio: zonificación ambiental (políticas ambientales de protección y conservación, restauración y aprovechamiento); zonificación funcional (uso ambientalmente recomendado) y lineamientos, regulaciones y normas ambientales. 
6. El modelo de ordenamiento ambiental nacional puso de manifiesto que para el sector agrícola y el pecuario existen condiciones favorables, expresadas en los usos potenciales altos y medios y que la problemática ambiental se encuentra caracterizada por el manejo inadecuado de los recursos naturales. Los resultados alcanzados fueron tributados al Esquema Nacional de Ordenamiento Territorial mostrando que el procedimiento puede ser parcialmente aplicado a esta escala y constituir un soporte importante para la etapa de análisis físico ambiental del ordenamiento territorial, pues algunos de sus componentes no resultan factibles de ejecutarse por diversas causas.

7. El modelo de ordenamiento ambiental regional de Yagüajay, demostró la efectividad del procedimiento, manifestando que las limitaciones ambientales y los potenciales de uso varían según las características propias de cada paisaje e identificó las incompatibilidades de uso y los conflictos sectoriales existentes. La propuesta de políticas, usos ambientalmente recomendados y lineamientos, regulaciones y normas constituyó un producto fundamental para la elaboración de la Estrategia de Desarrollo Integral del municipio, elaborada entre el 2013 y 2014, y en la actualización de su Plan General de Ordenamiento Territorial y Urbanismo.

\section{Bibliografía}

Alden, J., 2012. Regional development and spatial planning in an enlarged European Union. Ashgate Publishing, Ltd. Disponible en: http://books.google.es/books?hl=es\&lr=\&id=wTDoQBwjAY4C\&oi=fnd\&pg=PP1\&dq=spatial + planning $+\&$ ots $=$ YA3BWwxjOS\&sig=mmyesnOHnGc_UBg nRWf91AGVs14\#v=onepage\&q\&f=false. (Consulta: 03.06.2014).

ALFORJA, 2013. Técnicas participativas de apoyo a la estrategia. Disponible en: http://www.disaster-info.net/ desplazados/documentos/ escuelasaludable/60tecnicasparticipa.htm. (Consulta: 11.12.2013).

AMA-INSMET-GEF-PNUD, 2012. Impacto del Cambio Climático y Medidas de Adaptación en Cuba. Segunda Comunicación Nacional de Cuba al Convenio Marco de Naciones Unidas sobre Cambio Climático. GEF-PNUD. La Habana, 518 pp.

Arceo, S. y E. Salinas, 1994. Evaluación del potencial natural de los paisajes para la actividad agropecuaria en el ejemplo del municipio Yagüajay, Provincia de Sancti Spíritus, Cuba. Geographicalia (publicación no seriada). Zaragoza, pp. 3-16.

Arcia, M.I. et al., 1994. Geografía del medio ambiente. Una alternativa del Ordenamiento Ecológico. Colección Ciencia y Técnica/24. México D.F., 289 pp.

Asamblea Nacional del Poder Popular, 1997. Ley No. 81 del Medio Ambiente. Gaceta Oficial de la República de Cuba, Año XCV No 7. La Habana.

Barragán, J.M., 1994. Ordenación, Planificación y Gestión del Espacio Litoral. Editorial OIKOS-TAU. Barcelona, 293 pp. 
Barredo, J.I., 1996. Sistemas de Información Geográfica y evaluación multicriterio en la ordenación del territorio. RA-MA. Madrid, $261 \mathrm{pp}$.

Berti, C.G. y C.E. Ferrufino, 2009. Ordenamiento territorial en Centroamérica y República Dominicana: insumos para la construcción de una agenda regional. Conferencia Centroamericana por la Descentralización del Estado y el Desarrollo Local. Fundación Nacional para el Desarrollo. Disponible en: http://www.repo.funde.org/8/1/ORD-TERRIT.pdf. (Consulta: 30.06. 2014).

Cánovas, D., 2012. La Evaluación Ambiental Estratégica y el carácter vinculante del Ordenamiento Ambiental. Perspectivas. En: Convención Internacional Trópico 2012. La Habana.

Cárdenas, O., 2007. Análisis geoecológico de la subcuenca Seibabo. Revista MAPPING, No. 119. Madrid, pp. 26-33.

Cárdenas, O., 2012. Evaluación de la problemática ambiental existente en dos regiones de América Latina, con vistas a su ordenamiento ambiental. Revista MAPPING, No. 156. Madrid, pp. 54-60.

Cárdenas, O. y D. Hernández, 2014. Lineamientos ambientales como base para el ordenamiento ambiental de la cuenca del río San Diego, provincia de Pinar del Río, Cuba. Revista Ciencia de la Tierra y el Espacio, 2014 / enero-junio / Vol. 15 No. 1. La Habana.

Carranza, T., 2006. Guía campesina para la elaboración de Estudios de Ordenamiento Local-Comunitario. Delmo Comunicaciones S.A. de C. V. INE-SEMARNAT. México D.F., 184 pp.

Cavalcanti, A.P. et al., 1997. Desenvolvimiento sustentável e planejamento: bases teóricas e conceptuais. Teresina-PI: Editora da Universidade Federal de Piauí. Piauí, 251 pp.

Centro Nacional de Áreas Protegidas, 2013. Plan del Sistema Nacional de Áreas Protegidas. SNAPCNAP ISBN 978-959-287-049-9. La Habana, 362 pp.

CITMA, 1997. Estrategia Ambiental Nacional. Dirección de Medio Ambiente. La Habana, 23 pp.

CITMA, 2007. Resolución 40 / 2007. Estrategia Ambiental Nacional 2007/ 2010. La Habana, 66 pp.

CITMA, 2010. Proyecto de Estrategia Ambiental Nacional 2011/2015: Versión 1.1 La Habana, 48 pp.

CITMA, et al., 2008. El Ordenamiento Ambiental. En: Acciones prioritarias para consolidar la protección de la biodiversidad en el ecosistema Sabana-Camagüey. CUB/98/G32-CAPACIDAD 21. La Habana, 18 pp.

CITMA - CIGEA, 2009. Legislación Ambiental cubana relacionada con el manejo sostenible de tierras III. Editorial de Gestión Ambiental. La Habana, 159 pp.

CITMA - GEOCUBA Villa Clara y Sancti Spírirus, 1996. Estudio geográfico integral del municipio Yagüajay, norte de la provincia de Sancti Spíritus, Cuba. En: Proyecto GEF PNUD - CITMA. Publicaciones STT GEOCUBA-IC. Yagüajay, $201 \mathrm{pp}$.

CNAP - IGT, 2007. Cartografía digital de los ecosistemas costeros para la planificación y la gestión de áreas protegidas a escala 1:100 000 [inédito]. Instituto de Geografía Tropical. La Habana, $101 \mathrm{pp}$.

CEPAL, 2013. Guía análisis y zonificación de cuencas hidrográficas para el ordenamiento territorial. Subsecretaría de Desarrollo Regional y Administrativo. Centro de Documentación y Publicaciones, CEDOC-SUBDERE. Santiago de Chile, 138 pp. 
Comisión Centroamericana de Ambiente y Desarrollo, 2007. Lineamientos para la aplicación de la Evaluación Ambiental Estratégica en Centroamérica. En: Evaluación de Impacto Ambiental en Centroamérica una herramienta para el desarrollo sostenible. Disponible en: www.iucn. org/mesoamerica. (Consulta: 01.02.2011).

Comisión Nacional Permanente Peruana, 1998. Manual de Zonificación Ecológica - Económica para la Amazonia Peruana. EDIGRAFASA. Lima, 123 pp.

Córdoba, J.I., 2012. Planes de ordenamiento territorial, propiedad y medio ambiente (No. 6). Externado de Colombia. Disponible en: http://books.google.es/books?hl=es\&lr=\&id=yvTepyCph TQC\&oi=fnd\&pg=PA9\&dq=ordenamiento+territorial + am\%C3\%A9rica+latina\&ots=9Ed0gmHaKf \&sig=rUotx3M79yrQHwxO6fKdfiMZEk0 $\#_{\mathrm{v}}=$ onepage $\& \mathrm{q}=$ ordenamiento\%20territorial\%20am\% $\mathrm{C}$ 3\%A9rica\%20latina\&f=false. (Consulta: 24.06.2014).

Dourojeanni, A., 1993. Procedimientos de gestión para un desarrollo sustentable (aplicables a municipios, microrregiones y cuencas). Documento LC/G.1769, CEPAL-ILPES, ONU, División de Recursos Naturales y Energía. Santiago de Chile.

Duverger, I., 2014. Plan General de Ordenamiento Territorial y Plan de Desarrollo Integral. Revista de Ordenamiento Territorial y Urbanismo, No. 18, enero-junio. La Habana, pp. 31-38.

ECOARGENTINA, 2010. Atlas de indicadores ambientales para América Latina y el Caribe. Disponible en: http://www.ecoargentina.org/biodiversidad/indicadores-ambientales.htm. (Consulta: 05.01.2014)

Fernández, A. et al., 2009. Evaluación del medio ambiente cubano: GEO Cuba 2007. Agencia de Medio Ambiente-PNUMA. La Habana, 257 pp.

Gerhartz, J.L. et al., 2007. Metodología para la elaboración de planes de manejo en áreas protegidas de Cuba. Editorial Feijóo. La Habana, 89 pp.

Gligo, N., 1986. Medio ambiente en la planificación latinoamericana: vías para una mayor incorporación en La dimensión ambiental en la planificación del desarrollo. CEPAL/ILPES/PNUMA. Buenos Aires, 80 pp.

Gómez, C. y A. Gómez, 2013. Referencias para un análisis del desarrollo sostenible. UAH, Obras Colectivas de Ciencias, 10. Alcalá de Henares, 185 pp.

Gómez, D., 1994. Ordenación del territorio. Una aproximación desde el medio físico. Editorial Agrícola Española, S.A. Madrid, 238 pp.

Gómez, D., 2002. Ordenación Territorial. Coedición Ediciones Mundi-Prensa, Ed. Agrícola Española, S.A. Madrid, 704 pp.

González, T., I. García, 1998. Cuba. Su medio ambiente después de medio milenio. Editorial Científico Técnica. La Habana, 199 pp.

Guimarães, R., 2001. Fundamentos territoriales y biorregionales de la planificación. Serie Medio Ambiente y Desarrollo 39. Santiago de Chile.

Gutiérrez, F., 2010. Organización territorial, desarrollo sostenible y nuevas visiones sobre el territorio en Colombia (1991-2010). Perspectiva Geográfica, Vol. 15/2010. Bogotá, pp. 239-260.

Hernández, A. et al., 1999. Nueva Versión de clasificación genética de los suelos de Cuba. Instituto de Suelos. AGRINFOR. La Habana, 53 pp. 
Hernández, J.R., M. Bollo y A.P. Méndez, 2013. Ordenamiento ecológico general del territorio mexicano: enfoque metodológico y principales experiencias. Boletín de la Asociación de Geógrafos Españoles, (63). México D.F., pp. 33-55.

Hildebrand, A., 1996. Política de ordenación del territorio en Europa. Universidad de Sevilla, Consejería de Obras Públicas y Transportes de la Junta de Andalucía. Sevilla, 543 pp.

Instituto de Planificación Física, 1998. Guía para la elaboración del Plan General de Ordenamiento Territorial y urbanismo del municipio. Objetivos y procedimiento general [inédito]. La Habana, $51 \mathrm{pp}$.

Instituto de Planificación Física, 2007. Evaluación del impacto y vulnerabilidad de los asentamientos costeros por efecto de cambio climático y eventos meteorológicos severos. En: Escenarios de peligro y vulnerabilidad de la zona costera cubana, asociados al ascenso del nivel medio del mar para los años 2050 y 2100 [inédito]. La Habana, 98 pp.

Iñiguez, L., 2014. Recortes, escalas y actores ¿qué nos dicen los territorios?. En Universidad, conocimiento, innovación y desarrollo local. Ed. Universitaria Feliz Varela. La Habana, pp. 1-

Jiménez, R., 2012. Colombia: algunas consideraciones sobre su ordenamiento territorial. Revista Universidad EAFIT, 32(102). pp. 67-72.

Lima, A., 2006. Zoneamento Ecológico-Econômico. A luz dos direitos Socioambientais: Juruá. Editora Curitiba. Curitiba, 287 pp.

Lisio, A., 1996. Evaluación ambiental de la ciudad en el Caribe Insular. En: Los retos de la cooperación ambiental: el caso Caribe. Editorial Nueva Sociedad. Caracas, 118 pp.

Malczewski, J., 1999. GIS and Multicriteria Decision Analysis. John Wiley \& Sons. Nueva York, 392 pp.

Marinos, P., 2012, Sustainable Development and Spatial Planning: Some considerations arising from the case. European Journal of Spatial Development No. 46. Greek, 23 pp.

Martín, G., E. Salinas, J.M. Martínez, J. Olivera, et al., 2012. Mapa de paisajes del municipio de Yagüajay, a escala 1:25 000 [inédito]. Instituto de Geografía Tropical - Agencia de Medio Ambiente - Facultad de Geografía. La Habana.

Martínez, A.N. y A.N. Iglesia, 2005. Elementos jurídico-normativos de la ordenación ambiental del territorio en Argentina. Significado de la escala local de gestión. Revista Electrónica de Derecho Ambiental - Número 12-13.

Martínez, J.M., 1996. Mountain Geoecology and Sustainable Development. Background, Orientation and Prospects of Geographic Research. En: Cuban Contribution to the IGU Commissions and Study Groups. pp. 82-93.

Martínez, J.M., O. Cárdenas, G. Martín, J. Olivera, M. García, et al., 2010. Guía metodológica para los estudios técnicos de ordenamiento ambiental en Cuba [inédito]. Instituto de Geografía Tropical - Agencia de Medio Ambiente. La Habana, 36 pp.

Massiris, A., 2002. Ordenación del territorio en América Latina. Scripta Nova, Revista Electrónica de Geografía y Ciencias Sociales, Vol. VI, Número 125. Barcelona.

Massiris, A., 2005a. Fundamentos conceptuales y metodológicos del ordenamiento territorial. Universidad Pedagógica y Tecnológica de Colombia. Tunja, 122 pp. 
Massiris, A., 2005b. Guía conceptual y metodológica para la elaboración del modelo de uso y ocupación del territorio, el programa estatal y la gestión. En: Metodología para la formulación de prospectiva y modelo de ocupación de los programas estatales de ordenamiento territorial. Instituto de Geografía. UNAN. México D.F., 20 pp.

Mateo, J.M., 1984. Apuntes de Geografía de los Paisajes. Editorial ENPES. La Habana, 170 pp.

Mateo, J.M., 2008. Planificación ambiental. Material del curso de post grado de la maestría en Geografía, Ordenamiento Territorial y Medio Ambiente. Editorial Universitaria. La Habana, 92 pp.

Mateo, J.M. et al., 1989, Mapa de Paisajes. En: Nuevo Atlas Nacional de Cuba. Instituto de Geografía. Academia de Ciencias de Cuba. Ediciones Alber. Madrid, Sección XII 1.2-3.

Mateo, J.M. y E. Vicente da Silva, 2007. La Geoecología del Paisaje, como fundamento para el análisis ambiental. REDE-Revista Electrónica de PRODEMA, v. 1, n.1. Fortaleza, pp. 77-98.

Montes, P.F., 2001. El ordenamiento territorial como opción de políticas urbanas y regionales en América Latina y el Caribe División de Medio Ambiente y Asentamientos Humanos. Copyright ( $)$ Naciones Unidas. Medio Ambiente y Desarrollo No. 45, Naciones Unidas. Santiago de Chile, $61 \mathrm{pp}$.

Naciones Unidas, 1992. Programa 21: Un Plan de acción en pro del desarrollo sostenible. ISBN: 92-1-100509-4. New York.

Negrete, G. y G. Bocco, 2003.El ordenamiento ecológico comunitario. Gaceta ecológica 68:9-22. Disponible en: www.ine.gob.mx/publicaciones/new. (Consulta: 04.09.2010).

Nikolaeiv, V.A., 2006, La ciencia del Paisaje (en ruso). Facultad de Geografía, Universidad Estatal de Moscú. Moscú, 208 pp.

Othengrafen, F. y O. Sykes, 2013. Neo-liberalization processes and spatial planning in France, Germany, and the Netherlands: an exploration. Planning Practice \& Research, 28(1). pp. 141-159.

ONEI, 2011a. Anuario Estadístico de Cuba 2010. Disponible en http://www.one.cu/aec2010/datos/01\%20Territorio.pdf. (Consulta: 12.12.2012).

ONEI, 2011b. Anuario Estadístico de Yagüajay 2010. Disponible en: www.one.cu/aed2010/07 Sancti\%20Spiritus/Municipios/01Yaguajay/esp/Capitulos.htm. (Consulta: 8.10.2011).

Ornés, S., 2011. El urbanismo, la planificación urbana y el ordenamiento territorial desde la perspectiva del derecho urbanístico venezolano. Politeia, vol. 32, núm. 42, enero-junio. Caracas, pp. 197-225.

Padrón, J.R., 1992. Administración y protección del archipiélago de Los Roques. Problemas de una localidad aislada. En: Parque Nacional Archipiélago Los Roques. Edit. Torino. Caracas, pp. 145-162.

Partido Comunista de Cuba, 2011. Lineamientos de la Política Económica y social del Partido y la Revolución. En: VI Congreso del Partido Comunista de Cuba. La Habana, 38 pp.

Pérez, M., 2012. Avatares del ordenamiento territorial en Costa Rica. FLACSO. San José, 151 pp.

Petrov, K.M., 1989. Paisajes submarinos. Teoría, métodos e investigaciones. Editorial Nauka. Leningrado, pp. 38- 54. 
PNUMA, 2010. Perspectivas del medio ambiente: América Latina y el Caribe. GEO ALC 3. Copyright (C) 2010, PNUMA, Job Number. DEW/1077/PA.

Priego, A.G., et al., 2008. Propuesta para la generación semiautomatizada de unidades de paisajes. Serie Planeación Territorial. Morelia, $97 \mathrm{pp}$.

Ramón, A.M., 2010. Diseño metodológico para la elaboración de mapas de paisajes con el uso del SIG ArcGIS 9.3. CRECTEALC México-INADE. Puebla, 93 pp.

Ramón, A.M., E. Salinas y R. Remond, 2009. Diseño metodológico para la elaboración de mapas de paisajes con el uso de los SIG: aplicación a la cuenca alta del río Cauto, Cuba. GeoSIG, No.1, Volumen 1. Lujan, pp. 95-108.

Saenz de Buruaga, G., 1982. Sentido de la ordenación del territorio en la España actual. Estudios Territoriales No. 7. Barcelona, pp. 19.

Salinas, E., 1989. Paisajes de la Faja Tropical. Geografía Física de los Continentes II Parte. Facultad de Geografía, Universidad de La Habana. La Habana, pp. 201-477.

Salinas, E., 2005. La Geografía y el Ordenamiento Territorial en Cuba. La Gaceta Ecológica 76: 35-51 Instituto Nacional de Ecología. México D.F., pp. 9-34.

Salinas, E., 2013. Reflexiones acerca del papel del ordenamiento territorial en la planificación y gestión ambiental. Perspectiva Geográfica Vol. 18, No. 1. pp. 141-156.

Salinas, E. y J. Quintela, 2001. Paisajes y ordenamiento territorial: obtención del mapa de paisajes del estado de Hidalgo en México a escala media con el apoyo de los SIG. Revista de Investigación del Bajo Segura, Número 7. Madrid, pp. 517-527.

Sánchez, D., 2012. Aproximaciones a los conflictos sociales y propuestas sostenibles de urbanismo y ordenación del territorio en México. Revista de Estudios Sociales, núm. 42, abril. Bogotá, pp. $40-56$.

Secretaria de Medio Ambiente y Recursos Naturales, 2006. Manual del Proceso de Ordenamiento Ecológico. Impregrafica S.A. de C.V. México D.F., 317 pp.

Sochava, V.B., 1978. Introducción a la Teoría de los Geosistemas. Editorial Nauka, Novosibirsk. Moscú, 319 pp.

Spiridonov, A., 1981. Principios de la metodología de las investigaciones de campo y el mapeo geomorfológico. Editorial MES. La Habana, 75 pp.

Uriarte, M. y M. Fernández, 1998. Involucrando a la comunidad en la planificación. Manual para técnicos. Editorial Oficina del Historiador de La Habana. La Habana, 90 pp.

Urteaga, E., 2011. Modelos de Ordenación del Territorio en Europa: Francia, Alemania y Reino Unido. Estudios Geográficos Vol. LXXII, 270. pp. 263-289.

Vázquez, P., M. Sacido, M. y L. Zulaica, 2012. Técnicas de análisis para el ordenamiento territorial de cuencas agropecuarias: aplicaciones en la Pampa Austral, Argentina. Scripta Nova. Revista Electrónica de Geografía y Ciencias Sociales. Barcelona, 16 pp.

Vicente da Silva, E., J.M. Mateo, y A.J. de Andrade, 2011. Planejamento Ambiental e Bacias Hidrográficas. En: Planejamento e Gestão de Bacias Hidrográficas. Edições UFC. Fortaleza, 149 pp. 